\title{
(Photo)electrochemical Methods for the Determination of the Band Edge Positions of $\mathrm{TiO}_{2}$-Based Nanomaterials
}

\author{
Radim Beranek ${ }^{1,2,3}$ \\ ${ }^{1}$ Faculty of Chemistry and Biochemistry, Ruhr University Bochum, Universitätstr 150, NC4/073, D-44780 Bochum, Germany \\ ${ }^{2}$ Materials Research Department, Ruhr University Bochum, D-44801 Bochum, Germany \\ ${ }^{3}$ Research Department Interfacial Systems Chemistry, Ruhr University Bochum, D-44801 Bochum, Germany
}

Correspondence should be addressed to Radim Beranek, radim.beranek@rub.de

Received 30 September 2011; Accepted 15 December 2011

Academic Editor: Konstantin Neyman

Copyright ( 2011 Radim Beranek. This is an open access article distributed under the Creative Commons Attribution License, which permits unrestricted use, distribution, and reproduction in any medium, provided the original work is properly cited.

\begin{abstract}
$\mathrm{TiO}_{2}$-based nanomaterials play currently a major role in the development of novel photochemical systems and devices. One of the key parameters determining the photoactivity of $\mathrm{TiO}_{2}$-based materials is the position of the band edges. Although its knowledge is an important prerequisite for understanding and optimizing the performance of photochemical systems, it has been often rather neglected in recent research, particularly in the field of heterogeneous photocatalysis. This paper provides a concise account of main methods for the determination of the position of the band edges, particularly those suitable for measurements on nanostructured materials. In the first part, a survey of key photophysical and photochemical concepts necessary for understanding the energetics at the semiconductor/solution interface is provided. This is followed by a detailed discussion of several electrochemical, photoelectrochemical, and spectroelectrochemical methods that can be applied for the determination of band edge positions in compact and nanocrystalline thin films, as well as in nanocrystalline powders.
\end{abstract}

\section{Introduction}

Although first scientific reports of photoinduced effects of titanium dioxide on chemical reactions were available already more than ninety years ago [1-8], it was first in the 1970s that potential practical applications of $\mathrm{TiO}_{2}$ photoelectrochemistry and photocatalysis have been fully recognized. This was particularly due to the pioneering work of Fujishima and Honda on solar-driven water splitting into hydrogen and oxygen using a $\mathrm{TiO}_{2}$ photoanode [911], which promised utilization of $\mathrm{TiO}_{2}$-based materials for solar energy conversion and storage [12-16]. In following years further photochemical applications of $\mathrm{TiO}_{2}$ have been realized, most of them motivated particularly by the advantageous combination of its low cost, nontoxicity, and excellent stability against photocorrosion. One important example is the rapidly growing field of heterogeneous photocatalysis [17-25], in which $\mathrm{TiO}_{2}$ has been successfully employed in photooxidation reactions utilizing aerobic oxygen for the complete removal of pollutants from water and air [17-22, 24-39], in preparation of superhydrophilic and antifogging surfaces [40-43], in photocatalytic organic syntheses [4449], or in antitumor medicinal applications [50-54].

Importantly, although the bandgap energy of $\mathrm{TiO}_{2}$ is rather large (for anatase $3.2 \mathrm{eV} ; \sim 390 \mathrm{~nm}$ ) and direct bandto-band excitation can therefore only be achieved by highenergy UV light, the utilization of $\mathrm{TiO}_{2}$ is not confined to UV-light-driven applications. Drawing on the fundamental studies on dye sensitization of other wide bandgap semiconductors $\left(\mathrm{ZnO}, \mathrm{SnO}_{2}\right)$ in the 1960s [55-59], attaching visiblelight-absorbing organic dyes to the surface of $\mathrm{TiO}_{2}[60,61]$ has led to fabrication of regenerative dye-sensitized solar cells with the overall solar conversion efficiencies exceeding $10 \%$ [62-64]. Other sensitization approaches utilize chromophores like semiconductor quantum dots [65-70], plasmonic metal nanocrystals [71-75], simple coordination compounds like chloroplatinate (IV) complexes [29, 32, 76] or ferrocyanide ions [77-79], stable polymeric compounds $[38,39,80-83]$, or metal ions $\left(\mathrm{Cu}^{2+}, \mathrm{Fe}^{3+}\right)$ grafted onto the $\mathrm{TiO}_{2}$ surface $[84,85]$. In contrast to these surfaceconfined sensitization protocols, bulk-doping of $\mathrm{TiO}_{2}$ has also attracted significant interest. In the latter approach, 
transition metals [86-88] or main-group elements like carbon [35, 89], nitrogen [31, 90-97], and sulfur [98, 99] are introduced into the lattice of titania resulting in formation of intrabandgap donor and acceptor levels, allowing thus for visible light $(\lambda>400 \mathrm{~nm})$ excitation. Apart from the fields of solar cells and photocatalysis, the visible light-responsive $\mathrm{TiO}_{2}$ materials opened up a route for further developments including photoelectrochemistry-based sensors [100, 101] and light-addressable photoelectrochemical optoelectronic devices [102-106].

Obviously, many applications can benefit from $\mathrm{TiO}_{2}$ materials with fine-tuned structural and surface characteristics. Particularly nanostructured and mesoporous materials with a large surface-to-volume ration are highly profitable for most applications. This motivated the development of a great variety of synthetic protocols which allow for fabrication of $\mathrm{TiO}_{2}$ with well-defined morphologies on the micro- and nanoscale. These include, for example, nanoporous spheres [107], nanotubes [108, 109], hierarchical nanodendrite-nanoparticle composites [110], organized mesoporous $\mathrm{TiO}_{2}$ films with controlled crystallinity [111, 112], nanoparticles with distinct crystal facets [113, 114], or $\mathrm{TiO}_{2}$ inverse opals materials exhibiting photonic bandgap [115-117]. In addition, the modification of surface catalytic properties has been achieved, for instance, by coupling $\mathrm{TiO}_{2}$ with gold nanostructures [118], graphene [119], or reduced graphene oxide [120,121].

Notwithstanding the huge variety of different $\mathrm{TiO}_{2}$-based materials, it is important to realize that the fundamental basis for all photochemical applications of $\mathrm{TiO}_{2}$ is its semiconducting electronic structure [122, 125-129]. In other words, it is the energy band structure that underlies the photoactivity of $\mathrm{TiO}_{2}$-based materials, whereby the position of the band edges on the electrochemical potential scale exerts a crucial influence on the operation of the photochemical system. This can be well exemplified in Figure 1. A typical photocatalytic reaction at small $\mathrm{TiO}_{2}$ particles is initiated by absorption of a UV light photon, whereby a pair of charges is generated-an electron in the conduction band and a hole in the valence band (Figure 1(a)). The photogenerated charges can either recombine or undergo an interfacial electron transfer process, whereby the electron reduces an electron acceptor species $A$ to a primary reduction product $\mathrm{A}^{-\bullet}$, and the hole oxidizes an electron donor species to $\mathrm{D}^{+\bullet}$. Hence, for example, during a typical photocatalytic oxidation of organic pollutants on $\mathrm{TiO}_{2}$ in aqueous solutions, the reacting holes are scavenged either directly by the pollutant or by adsorbed hydroxyl ions to produced hydroxyl radicals which can then oxidize the pollutant due to their high oxidizing power. Simultaneously, the photogenerated electrons reduce molecular oxygen to a superoxide radical $\left(E_{\mathrm{O}_{2} / \mathrm{O}_{2}}{ }^{-}=-0.16 \mathrm{~V}\right.$ versus NHE [130]) which can then undergo further reactions to produce hydroxyl radicals [17, 131-134]. It is obvious that the positions of the conduction and valence band edges are of crucial importance here since these give information on the reductive and oxidative power of photogenerated electrons and holes, respectively. Interestingly, the product of the one-hole oxidation of some electron donors-like, for example, the methoxy radical as a primary oxidation product of methanol (Figure $1(\mathrm{~b})$ ) - is a very strong reducing agent that can inject an electron into the conduction band of $\mathrm{TiO}_{2}$ and is thereby further oxidized to formaldehyde. Since this generation of two electrons in the conduction band upon absorption of one photon has been first observed during photocurrent measurements, it has been coined as the photocurrent-doubling effect (photocurrentmultiplication effect) [125]. It goes without saying that the position of the conduction band edge on the potential scale will again play an essential role for the efficiency of the electron injection in such a case. Obviously, similar consideration will be also valid in cases when the photoprocess is based on light absorption by a sensitizer, typically a dye (Figure 1(c)). Here, the dye gets into an excited state from which it injects an electron into the conduction band of a semiconductor and is thereby oxidized. Alternatively to this photoinduced electron transfer scenario, in case of a strong coupling between the sensitizer and $\mathrm{TiO}_{2}$ the so-called direct optical electron transfer from the chromophore's HOMO into the conduction band of $\mathrm{TiO}_{2}$ can occur, as known, for example, for $\mathrm{TiO}_{2}$ covalently sensitized with catechol [135-137], chlorophenols [138, 139], or polymeric compounds [140]. In case of $\mathrm{TiO}_{2}$-assisted photooxidation reactions based on sensitization, one often speaks about "indirect photocatalysis" since the reaction is not initiated through direct photon absorption by $\mathrm{TiO}_{2}$ ("direct photocatalysis"; Figure 1(a)), but instead indirectly, through the light absorption by a dye $[24,25,34,37]$. At any rate, the position of the conduction band edge must be positive enough in order to allow for the injection from the dye, and at the same time negative enough, in order to allow for further electron transfer to suitable acceptors in the solution (e.g., oxygen).

From the above stated, it is clear that the positions of the band edges exert a crucial influence on the photoactivity of $\mathrm{TiO}_{2}$-based materials. In this context, it is rather surprising that the determination of the band edge position is still only very rarely directly addressed experimentally, particularly in research directed to the development of new photocatalysts. This causes a serious lacuna in our understanding of the photoactivity of such novel materials since the position of the band edges in many cases cannot be simply predicted or taken from the literature data. This is due to the fact that the band edge positions of $\mathrm{TiO}_{2}$-based materials will normally depend on surface charging. This will be highly dependent not only on the ionic conditions in a concrete electrolyte ( $\mathrm{pH}$, specific adsorption of ions), but also on the surface structure and composition of the material, which, in turn, will depend on the particular synthetic strategy used for the fabrication. The aim of this paper is to review various methods for the measurement of the band edge positions of $\mathrm{TiO}_{2}$ based materials. The focus will be particularly on nanostructured materials used in photocatalysis and other applications operating in aqueous electrolytes. The paper will start with a short summary of some fundamental concepts of semiconductor photophysics and photochemistry (quasi-Fermi levels, flatband potential, $\mathrm{pH}$ dependence of band edges) that are directly relevant for understanding the problem of band edge determination. Then, a theoretical approach to the calculation of the band edges position, together with 


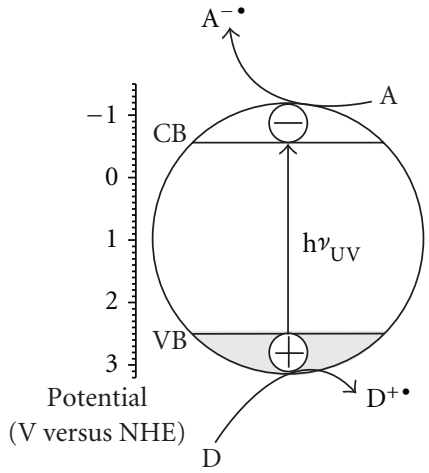

(a)

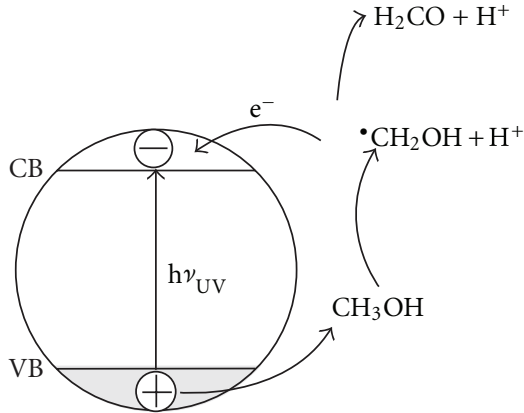

(b)

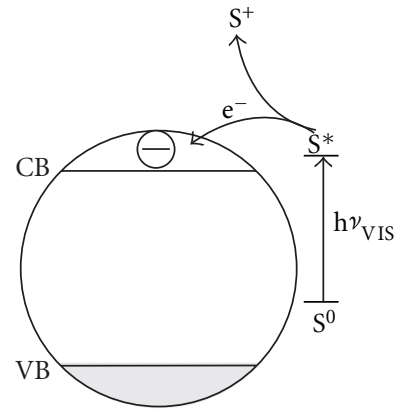

(c)

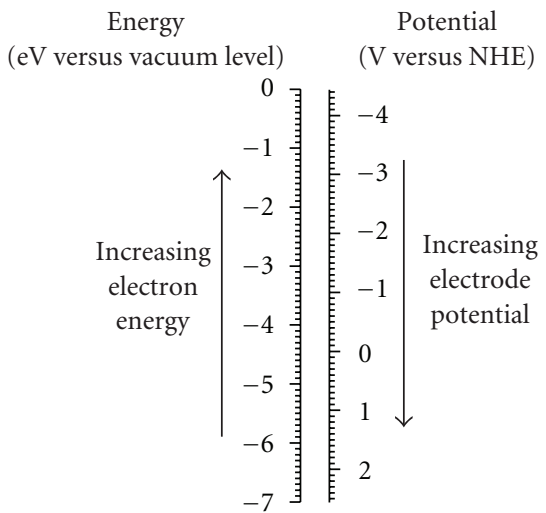

(d)

FIGURE 1: Schematic view of different $\mathrm{TiO}_{2}$-assisted photoprocesses. (a) Direct photocatalysis initiated by excitation of an electron from the valence band $(\mathrm{VB})$ to the conduction band $(\mathrm{CB})$ of $\mathrm{TiO}_{2}$. (b) Mechanism of "photocurrent multiplication" at an irradiated $\mathrm{TiO}_{2}$ electrode in the presence of methanol. (c) Sensitization of $\mathrm{TiO}_{2}$ by a dye: the dye is photoexcited with visible light from its ground state $S^{0}$ to excited state $\mathrm{S}^{*}$, injects an electron to the conduction band of $\mathrm{TiO}_{2}$, and is thereby oxidized to $\mathrm{S}^{+}$. All recombination pathways are omitted for the sake of clarity. Whereas the common convention in solid state physics relates the positions of band edges with respect to the vacuum level, in photoelectrochemistry and photocatalysis, the potentials are usually given with respect to the normal hydrogen electrode (NHE; $E_{\mathrm{NHE}}=0 \mathrm{~V}$ ). On the energy scale, the NHE is reported to lie at $-4.44 \pm 0.02 \mathrm{eV}$ (at $298.15 \mathrm{~K}$ ) with respect to the vacuum level [122]; for more details, see $[123,124]$.

the application of conventional spectroscopic and contact potential difference measurements, will be shortly discussed. This will be followed by a detailed discussion of various electrochemical, photoelectrochemical, and spectroelectrochemical methods that can be applied to measurements on $\mathrm{TiO}_{2}$-based materials in the form of thin compact films, porous nanocrystalline layers, and nanocrystalline powders.

\section{Theory and Fundamental Concepts}

2.1. Quasi-Fermi Levels and Flatband Potential. $\mathrm{TiO}_{2}$ is typically found in one of its three main crystal structures: rutile (tetragonal), anatase (tetragonal), or brookite (orthorhombic). Out of these, anatase is the polymorph most widely used for photocatalytic and photoelectrochemical purposes. It is noteworthy that the conduction band edge states have predominantly the Ti $3 d$ character, while the valence-band edge states have the $\mathrm{O} 2 p$ character. Importantly, due to its inherent nonstoichiometry (oxygen vacancies), $\mathrm{TiO}_{2}$ is typically a rather heavily doped n-type semiconductor. This means that its Fermi level $\left(E_{\mathrm{F}}\right)$ is typically right below the conduction band edge $\left(E_{\mathrm{C}}\right)$. From the thermodynamic point of view, the Fermi level is the electrochemical potential of the electron in the solid. Equivalently, from the statistical point of view, the Fermi level is the energy at which the probability of an energy level being occupied by an electron (the Fermi function) is 0.5 (Note, however, that this does not imply that the level at the Fermi energy is populated by electrons because the population depends upon the product of the Fermi function and the electron density of states). Hence, the Fermi level describes the occupation of energy levels in a semiconductor at thermodynamic equilibrium. However, the condition of thermodynamic equilibrium is not always fulfilled-particularly when excess electrons and holes are photogenerated under illumination or injected under electric bias. Accordingly, the electron and hole densities in the conduction and valence band are not described by the same Fermi level but by a quasi-Fermi level of electrons $\left({ }^{*} E_{\mathrm{Fn}}\right)$ and a quasi-Fermi level of holes $\left({ }^{*} E_{\mathrm{Fp}}\right)$, respectively (Figure 2 ) $[125,126,128]$. In general, the density of majority carriers 


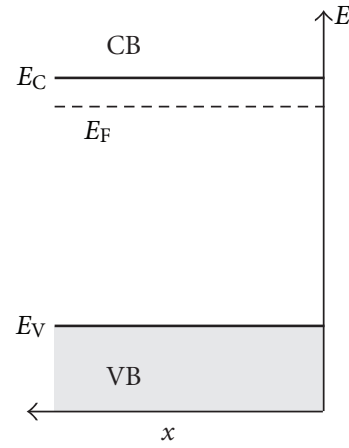

(a)

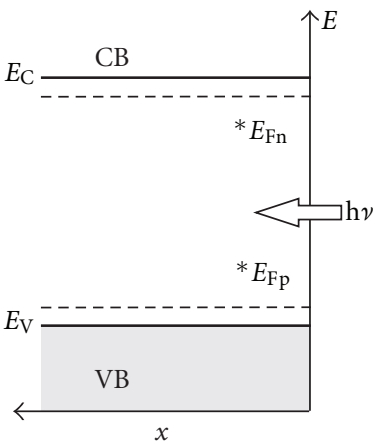

(b)

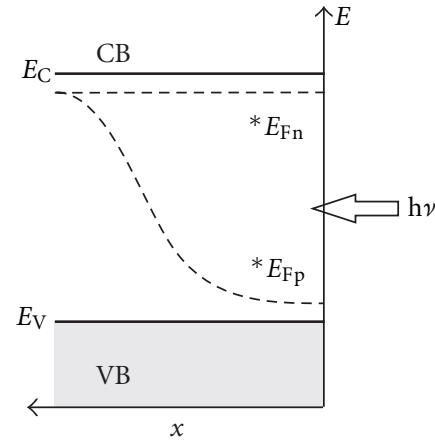

(c)

Figure 2: Fermi levels and quasi-Fermi levels of electrons and holes for an n-type semiconductor: (a) at thermodynamic equilibrium (in the dark); (b) and (c) under illumination; (c) local excitation; $x$ is the distance from the semiconductor surface (adapted from [128]).

(electrons in case of $\mathrm{TiO}_{2}$ ) does not significantly increase upon illumination and the quasi-Fermi level for majority carriers is normally almost the same as the Fermi level at equilibrium. In contrast, the density of minority carriers (holes) can be increased by many orders of magnitude, which then leads to a shift of the quasi-Fermi level of holes $\left({ }^{*} E_{\mathrm{Fp}}\right)$ downwards to the vicinity of the valence band edge.

It should be also noted that the generation of electronhole pairs often occurs locally near the semiconductor surface due to the small penetration depth of light, which leads to variations in the quasi-Fermi level of holes with the distance from the surface (Figure 2(c)). Importantly, in case of heavily doped n-type metal oxides like $\mathrm{TiO}_{2}$, the lower conduction band edge, $E_{\mathrm{C}}$, practically merges with the quasiFermi level for electrons, ${ }^{*} E_{\mathrm{Fn}},\left(\left|E_{\mathrm{C}}-{ }^{*} E_{\mathrm{Fn}}\right|<0.1 V\right)[125]$. Therefore, as will be discussed below in more detail, the determination of the conduction band edge often translates into the measurement of the position of the quasi-Fermi level of electrons. Once this is known, the position of the valence band edge can be simply calculated by adding the value of bandgap energy, that is, typically determined by optical $[128,141-151]$ or photoelectrochemical methods [152-156].

Another important concept, particularly in case of compact flat $\mathrm{TiO}_{2}$ films that behave similarly to single crystal semiconductors, is the flatband potential. First, let us consider the energetic situation at the n-type semiconductor/ electrolyte interface before and after the contact of the two phases (Figure 3). After the contact of the semiconductor surface with the electrolyte, the thermodynamic equilibrium on both sides of the interface must be established [125-128, 157]. In other words, the Fermi level of the semiconductor $E_{\mathrm{F}}$ is adjusted to the Fermi level of the electrolyte $E_{\mathrm{F} \text {,redox }}$. The latter can be considered nearly constant because the number of available states per unit energy in the solution typically far exceeds the number present in a semiconductor. This equilibration happens through electron transfer across the interface, which results in formation of the space-charge layeralso called the "depletion layer" since the surface region of the semiconductor is depleted of its majority carriers. It is important to realize that, in the case of an n-type semiconductor, this interfacial charge-transfer process produces an excess of positive charges in the semiconductor (immobile charges of ionized donors) and an excess of negative charges in the electrolyte. With more electrons exchanged, the electric field of the negative charges on the solution side hinders further electron transfer so that the equilibrium is established in which no net charge flow occurs. As a consequence, the bands are bent upwards, which can be understood in terms of a continuously growing barrier for interfacial electron transfer when moving from the bulk of the semiconductor to the interface due to the continuously less efficient screening of the negative charges in the solution by the positive charges in the depletion layer [127]. The height of the barrier is the energy difference between the conduction band edge in the bulk $\left(E_{\mathrm{C}}\right)$ semiconductor and the conduction band edge at the surface $\left(E_{\mathrm{C}, \mathrm{S}}\right)$ and corresponds to the potential drop in the space-charge layer $U_{S}$.

The charge distribution scenario at semiconductor/electrolyte interface is summarized in Figure 4. Importantly, three distinct double layers can be distinguished at the interface. First, it is the semiconductor space-charge layer with positive charges in the form of ionized donors and the counter negative charge located at the surface. The second one is the Helmholtz double layer consisting of the inner Helmholtz plane (IHP) and the outer Helmholtz plane (OHP). The first is located at the semiconductor surface, and the charge is in the surface states or at the location of specifically adsorbed ions, whereas the latter denotes the position of the closest approach of hydrated mobile ions. Finally, there is the Gouy-Chapman layer which is extended region with an excess of free ions of one sign. Essentially, the double layers act as parallel-plate capacitors connected in series with capacitances $C_{\mathrm{SC}}, C_{\mathrm{H}}$, and $C_{\mathrm{G}}$ representing the capacitance of the space-charge layer, the capacitance of the Helmholtz double layer, and the capacitance of the Gouy-Chapman layer, respectively, whereby $C_{G}$ can be typically neglected for electrolytes containing relatively high concentrations of redox species (Figure 4(d)).

The simplest quantitative description of the situation at the semiconductor/electrolyte interface $[125-129,157]$ is analogous to the Schottky diode model and is based on the following assumptions: (i) ideal, crystalline semiconductor, 


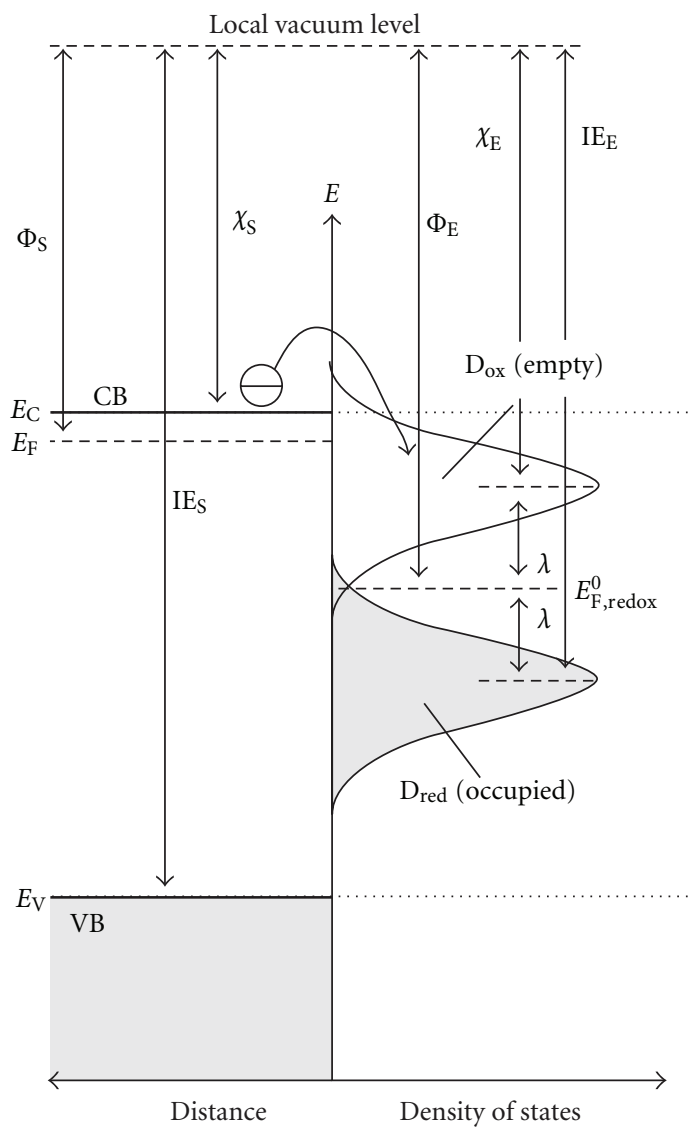

(a)

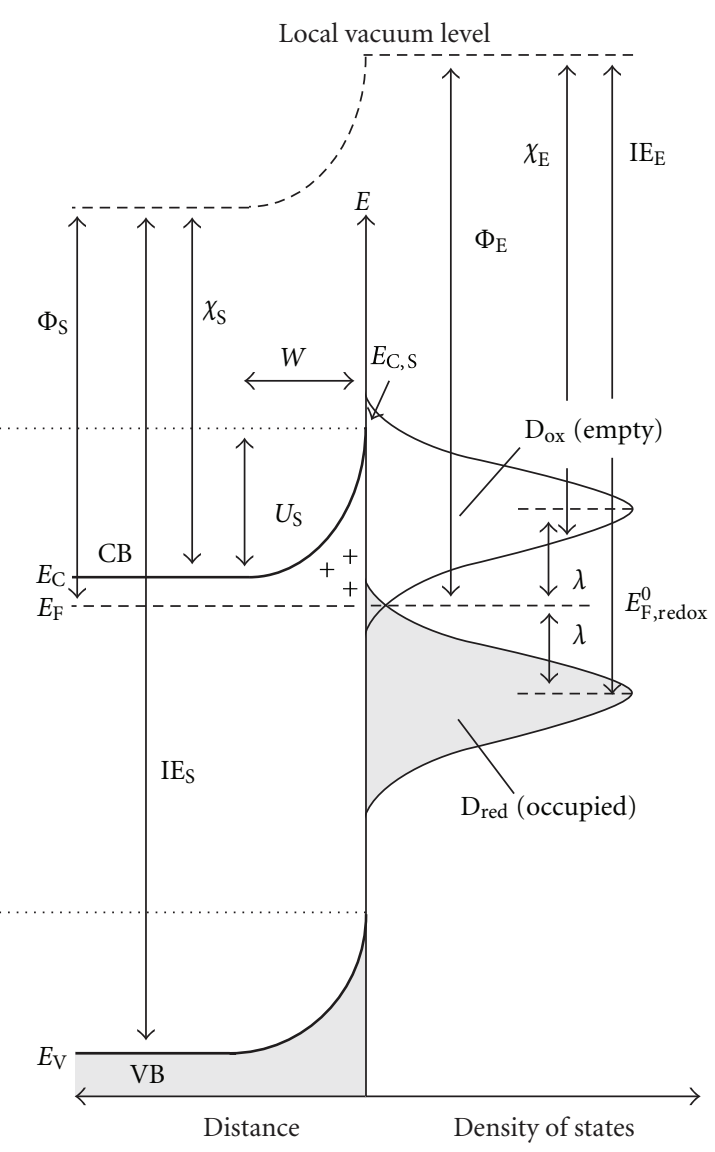

(b)

FIGURE 3: Schematic energy model of the n-type semiconductor/electrolyte interface before (a) and after (b) the establishment of equilibrium. The presence of surface states in the semiconductor is neglected. $D_{\text {red }}$ and $D_{\mathrm{ox}}$ correspond to the distribution functions of the density of states for reduced and oxidized species, respectively, of the redox system (the energy distribution of reduced and oxidized species is different due to different solvation; $\lambda$ is the reorganization energy). $\Phi, \chi$, and $I E$ are the work function, electron affinity, and ionization energy, respectively, of the semiconductor (index $\mathrm{S}$ ) and of the electrolyte (index $\mathrm{E}$ ).

homogeneous donor level near the conduction band (oxygen vacancies in the form of $\mathrm{Ti}^{3+}$ sites in case of $\mathrm{TiO}_{2}$ ) with all donors ionized (all the electrons from the $\mathrm{Ti}^{3+}$ donors have been thermally excited to the conduction band); (ii) no surface states; (iii) potential drop in the Helmholtz layer can be neglected. The potential and charge distribution within the space-charge layer can be then described by a onedimensional Poisson equation:

$$
\frac{\partial^{2} \varphi}{\partial x^{2}}=-\frac{1}{\varepsilon \varepsilon_{0}} \rho,
$$

where $\varphi$ is potential, $x$ is distance, $\varepsilon$ and $\varepsilon_{0}$ are the relative permittivity of the semiconductor and the permittivity of vacuum, respectively, and $\rho$ is the volume charge density. After two integrations assuming $\rho=q N$ ( $q$ is the elementary charge; $N$ is the doping concentration) and the boundary conditions $d \varphi / d x=0$ for $x=W$ and $\varphi=0$ for $x=W$ (see $[125,126,128]$ for details), one obtains the following relation for the width of the space-charge layer $W$ :

$$
W=\left|\frac{2 \varepsilon \varepsilon_{0}}{q N}\left(U_{\mathrm{S}}-\frac{k T}{q}\right)\right|^{1 / 2},
$$

where $U_{\mathrm{S}}$ is the potential drop in the space-charge layer which can be obtained as

$$
U_{\mathrm{S}}=E_{\mathrm{appl}}-E_{\mathrm{FB}} \quad \text { (with external polarization) }
$$

$$
U_{\mathrm{S}}=E_{\mathrm{F}, \text { redox }}-E_{\mathrm{FB}} \quad \text { (without external polarization), }
$$

where $E_{\text {appl }}$ is externally applied potential and $E_{\mathrm{FB}}$ is the potential at which $U_{S}=0$ and the bands in the semiconductor are "flat" (flatband potential). It is now clear that the value of $E_{\mathrm{FB}}$ is of fundamental significance since it gives a direct information on the position of the conduction band 


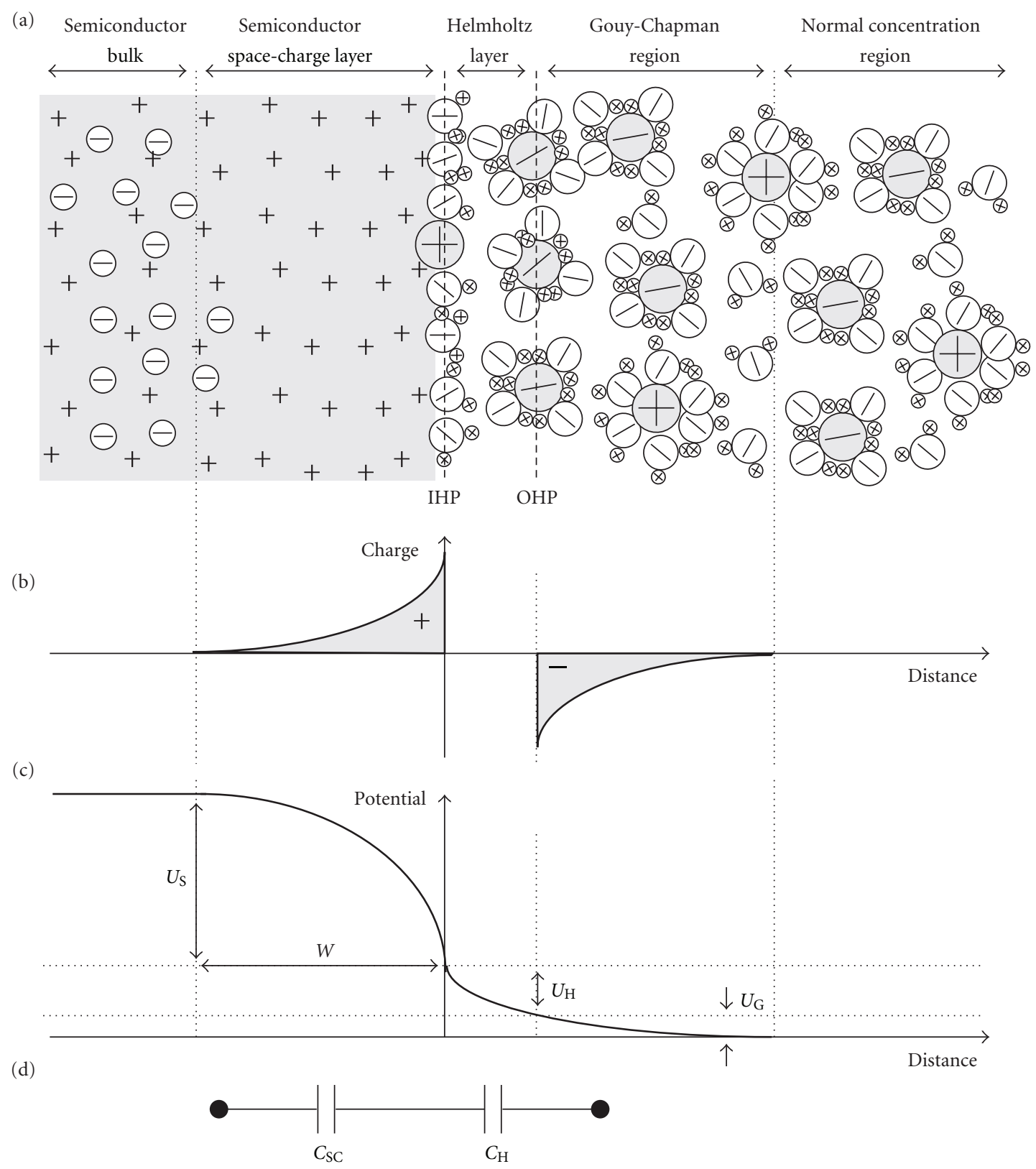

FIGURE 4: Schematic view of the electric double layers at the n-type semiconductor/aqueous electrolyte interface (a) with corresponding charge (b) and potential (b) distributions. $U_{\mathrm{S}}$ is the potential drop across the space-charge layer, $U_{\mathrm{H}}$ is the potential drop in the Helmholtz layer, and $U_{\mathrm{G}}$ represents the drop in the Gouy-Chapman layer; (d) the equivalent circuit for the interface assuming that $U_{\mathrm{G}}$ can be neglected.

edge at the n-type semiconductor's surface $\left(E_{\mathrm{C}, \mathrm{S}}\right)$, assuming that the difference between $E_{\mathrm{FB}}$ and $E_{\mathrm{C}, \mathrm{S}}$ is very small for doped semiconductors. In other words, the determination of the conduction band edge of thin compact $\mathrm{TiO}_{2}$ films often translates into the measurement of the flatband potential (for more details, see below). However, it should be emphasized that, in the context of nanomaterials, the above described formalism applies only to thin compact highly doped $\mathrm{TiO}_{2}$ films that behave in a manner similar to compact crystalline semiconductors. In contrast, in small $\mathrm{TiO}_{2}$ particles and in highly porous nanocrystalline electrodes, the formation of the space-charge layer is improbable due to the very small crystallite size [158-163]. In other words, the nearly depleted small $\mathrm{TiO}_{2}$ crystals do not contain enough electrons in order to create an effective space-charge layer. Several methods suitable for the determination of band edges in such nanocrystalline systems will be presented below.

2.2. pH Dependence of the Position of Band Edges. The position of the band edges at the surface $\left(E_{C, S}\right)$ is determined by the charge at the surface, that is, by the potential drop in the Helmholtz layer $U_{\mathrm{H}}$ :

$$
E_{\mathrm{C}, \mathrm{S}}=E_{\mathrm{C}, \mathrm{S}}^{0}-q U_{\mathrm{H}},
$$




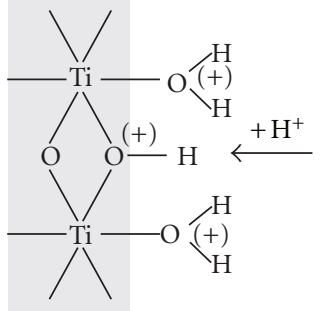

$\mathrm{pH}<\mathrm{pH}_{\mathrm{IEP}}$

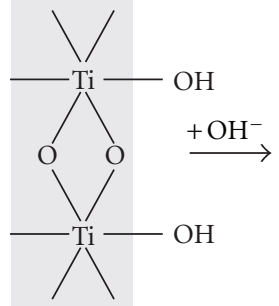

$\mathrm{pH}=\mathrm{pH}_{\mathrm{IEP}}$

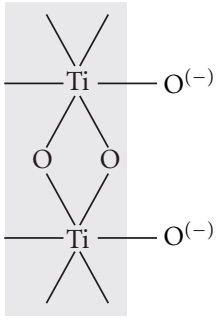

$\mathrm{pH}>\mathrm{pH}_{\mathrm{IEP}}$

FIGURE 5: Simplified scheme of the protonation and deprotonation of hydroxylated $\mathrm{TiO}_{2}$ surface leading to positive and negative net charge at the surface, respectively. The isoelectric point $\left(\mathrm{pH}_{\mathrm{IEP}}\right)$ of $\mathrm{TiO}_{2}$ is typically ca. $5.8-7.5[125,164-167]$. The $p K_{A}$ values of monodentate and bidentate $\mathrm{OH}$ groups are reported to be 12.7 and 2.9 , respectively [166].

where $E_{C, S}^{0}$ is the position (on the energy scale) of the conduction band edge at the surface at $U_{\mathrm{H}}=0$. The Helmholtz double layer at semiconductors is typically determined through adsorption and desorption processes, which is particularly true for ionic oxide semiconductors like $\mathrm{TiO}_{2}$ in aqueous electrolytes. In this case, the protons and hydroxyl groups play an essential role while the specific adsorption of other ions can be in most cases neglected.

In essence, the lattice $\mathrm{Ti}$ atoms act as Lewis acid sites and make the adsorption of hydroxyl ions possible, whereas the bridging lattice oxygen attracts protons and acts thereby as a Lewis base site. Hence, depending on the $\mathrm{pH}$, the semiconductor surface becomes charged either positively or negatively (Figure 5 ). The $\mathrm{pH}$ value at which the net surface charge is zero is called the isoelectric point $\left(\mathrm{pH}_{\mathrm{IEP}}\right)$ or the point of zero zeta potential (pzzp). (Here, it should be noted that $\mathrm{pH}_{\mathrm{IEP}}$ and pzzp are not necessarily identical with the point of zero charge, pzc, that denotes the $\mathrm{pH}$ value at which $\mathrm{H}^{+}$and $\mathrm{OH}^{-}$are adsorbed in equal amounts; when other ions than $\mathrm{H}^{+}$and $\mathrm{OH}^{-}$are present and influence the charging of the surface, the pzc and the $\mathrm{pH}_{\text {IEP }}$ are not equal). The $\mathrm{pH}$ dependence of the conduction band edge at the surface can be then derived as follows [125]. Assuming $\mathrm{pH}<$ $\mathrm{pH}_{\mathrm{IEP}}$, we obtain the following equilibrium reaction:

$$
\mathrm{H}_{3} \mathrm{O}^{+} \rightleftharpoons \mathrm{H}_{\mathrm{S}}^{+}+\mathrm{H}_{2} \mathrm{O},
$$

where $\mathrm{H}_{3} \mathrm{O}^{+}$is a hydroxonium ion in the solution and $\mathrm{H}_{\mathrm{S}}{ }^{+}$is an adsorbed proton. The equilibrium is described by

$$
\frac{\left[\mathrm{H}_{\mathrm{S}}{ }^{+}\right]}{\left[\mathrm{H}_{3} \mathrm{O}^{+}\right]}=\exp \left(-\frac{\Delta G}{k T}\right)=A \exp \left(\frac{-q U_{H}}{k T}\right),
$$

where $\Delta G$ is the free Gibbs energy, $U_{\mathrm{H}}$ is the potential drop in the Helmholtz double layer, and $A$ is a constant (assuming that $\Delta G$ varies linearly with $\left.U_{\mathrm{H}}\right)$. Assuming $\left[\mathrm{H}_{3} \mathrm{O}^{+}\right] \gg$ $\left[\mathrm{H}_{\mathrm{S}}{ }^{+}\right]$, the following relation can be obtained:

$$
q U_{\mathrm{H}}=B+k T \ln \left[\mathrm{H}_{3} \mathrm{O}^{+}\right]=B-2.3 k T \mathrm{pH},
$$

in which $B=2.3 k T\left(\mathrm{pH}_{\mathrm{IEP}}\right)$ assuming $U_{\mathrm{H}}=0$ at $\mathrm{pH}_{\mathrm{IEP}}$. By combining (5) and (8), we obtain now

$$
E_{\mathrm{C}, \mathrm{S}}=E_{\mathrm{C}, \mathrm{S}}^{0}+2.3 k T\left(\mathrm{pH}-\mathrm{pH}_{\mathrm{IEP}}\right) .
$$

Accordingly, with increasing $\mathrm{pH}$, the band edges at the surface shift to higher energies (on the energy scale), that is, to more cathodic potentials (on the electrode potential scale), whereby the shift at $298 \mathrm{~K}$ is typically $\sim 0.059 \mathrm{~V} / \mathrm{pH}$ unit.

2.3. Non-Ideal Behavior due to Surface States. The theoretical considerations described in Sections 2.1 and 2.2 assume that the charging of the semiconductor surface (i.e., the position of its band edges) is independent of the applied potential (applied bias voltage is effectively "consumed" within the space-charge layer) or irradiation (minority charge carriers are efficiently scavenged by species in the electrolyte). However, many semiconductors can have localized surface energy levels in the bandgap — the so-called "surface states"—which are typically related to crystal defects or surface damage, or they may result from surface reactions occurring in the dark or under illumination [128, 168, 169]. Obviously, relatively high density of surface states can be present at the surface of doped or surface-modified $\mathrm{TiO}_{2}$-based materials. It is important to realize that the presence of surface states can have significant effects on the position of band edges. During electrode polarization, the Fermi level can match the energy level of the surface states, which will lead to their charging. This might result in the change of the net charge at the surface (i.e., change in the potential drop across the Helmholtz layer), which will cause a shift of the band edge positions. Similarly, during irradiation, the surface states may act as traps for photogenerated charge carriers. Thus, for example, the minority charge carriers (holes in case of $n$ type $\mathrm{TiO}_{2}$ ) or charged surface intermediates can accumulate at the surface, which will again lead to changes in the surface charging and result in "unpinning" of band edges [170]. In photoelectrochemical experiments, these problems can be to some extent avoided by adding efficient scavengers of minority charge carriers into the electrolyte [171].

2.4. Theoretical Predictions of the Position of Band Edges. Butler and Ginley introduced a theoretical approach for the prediction of the position of band edges using the following relation $[125,164]$ :

$$
E_{\mathrm{C}, \mathrm{S}}^{0}=E^{\mathrm{e}}-X+\frac{1}{2} E_{\mathrm{g}},
$$

where $E^{\mathrm{e}}$ is the energy of free electrons on the hydrogen scale $(4.44 \pm 0.02 \mathrm{eV}), E_{\mathrm{g}}$ is the bandgap energy, and $X$ is the Sanderson electronegativity of the semiconductor, expressed as the geometric mean of the electronegativities of the constituent atoms, which are defined after Mulliken as the arithmetic mean of the atomic electron affinity and the first ionization energy (both in eV). Calculation for $\mathrm{TiO}_{2}$ gives $X=5.8 \mathrm{eV}$, which (assuming $(1 / 2) E_{\mathrm{g}}=1.6 \mathrm{eV}$ for anatase) yields the value of $E_{\mathrm{C}, S}^{0}$ of $+0.24 \mathrm{eV}$ (relative to standard hydrogen electrode on the energy scale, i.e., $-0.24 \mathrm{~V}$ versus NHE on the electrode potential scale). Interestingly, this result is only by $\sim 0.1 \mathrm{~V}$ more negative than experimental results obtained by measurements on anatase single crystals [172]. Although several more sophfisticated theories based on DFT calculations have been developed recently [173175], the theoretical predictions cannot be always expected 
to yield sufficiently reliable results, mainly in case of doped and surface-modified $\mathrm{TiO}_{2}$-based materials.

\subsection{Spectroscopic and Contact Potential Difference Techniques.} Obviously, some key quantities related to the positions of energy bands (see Figure 3) can be obtained also from spectroscopic and contact potential difference measurements performed in a "dry" (or "semidry") state. Thus, for example, the ionization energy of the semiconductor $\left(I E_{S}\right.$, defined as the energy needed to excite an electron from the valence band edge at the surface to the local vacuum level) can be measured by photoemission spectroscopy (e.g., UPS) [176]. On the other hand, the Kelvin probe method can be used for determination of the contact potential difference $(C P D)$, that is, of the difference between the work function of a semiconductor and the work function of the metal tip of the probe (with known position on the energy vacuum scale) [177]. Moreover, the latter technique can be combined with illumination in the so-called surface photovoltage spectroscopy in which the changes of the CPD (i.e., of surface voltage) upon illumination are measured $[178,179]$. Importantly, the saturation surface photovoltage is then directly related to the difference of the position of the Fermi level in the dark and the position of the quasi-Fermi level under illumination [180]. As an alternative to the Kelvin probe technique, the surface photovoltage can be also measured directly utilizing a metal-insulator-semiconductor structure and using chopped illumination in conjunction with lock-in detection of the surface photovoltage signal $[178,179]$. Importantly in the context of this paper, a standard surface photovoltage measurement can typically be performed also in the presence of adsorbents like water molecules at the surface of the semiconductor ("semidry" state) [181]. Moreover, the Kelvin probe measurements of photoelectrodes immersed into electrolyte have been reported, whereby the electrode and the electrolyte were separated from the Kelvin probe tip by a very thin glass plate [182]. This method has been, for example, used for the estimation of the quasi-Fermi level in the $\mathrm{TiO}_{2}$ nanocrystalline layers of dye-sensitized solar cells [183].

A more detailed discussion of these approaches is beyond the scope of this paper. Herein, we deal mainly with $\mathrm{TiO}_{2}$-based materials for use in photocatalysis and photoelectrochemistry and the focus is on electrochemical and photoelectrochemical methods addressing the band energetics directly under operational conditions in (mostly aqueous) solutions. As already mentioned, experimentally the problem of determination of the band edge position is typically addressed by the measurement of the flatband potential or of the quasi-Fermi level. Several electrochemical, photoelectrochemical, and spectroelectrochemical methods will be now discussed in more detail.

\section{3. (Photo)electrochemical Methods}

3.1. Capacitance Measurements on Thin Compact Films. As already noted above, since thin compact $\mathrm{TiO}_{2}$ films (e.g., dense anodic $\mathrm{TiO}_{2}$ films on $\mathrm{Ti}$ ) behave similarly to conventional macroscopic semiconductor electrodes, the Schottky formalism can be applied and their conduction band edge potential can be measured as the flatband potential. Using the model of a parallel-plate capacitor, the Mott-Schottky relation can be obtained from (2):

$$
\frac{1}{C_{\mathrm{SC}}^{2}}=\frac{2}{\varepsilon \varepsilon_{0} q N_{D}}\left(E_{\mathrm{appl}}-E_{\mathrm{FB}}-\frac{k T}{q}\right) .
$$

The interface double layer capacitances $C_{\mathrm{SC}}$ and $C_{\mathrm{H}}$ can be treated as two capacitors connected in series (Figure $4(d)$ ). The overall capacitance $C$ is then given by

$$
\frac{1}{C}=\frac{1}{C_{\mathrm{SC}}}+\frac{1}{C_{\mathrm{H}}} .
$$

Under some conditions (a single crystal-like behavior, moderate doping, surface states neglected), it can be assumed that the width of the space-charge layer is much larger than the width of the Helmholtz layer, which yields $C_{\mathrm{SC}} \ll C_{\mathrm{H}}$ and, accordingly, $C \cong C_{S C}$.

A widely used technique for the determination of the capacitance is the measurement of impedance. In these experiments, an $a c$-voltage signal of small amplitude is used for the perturbation of the sample. From the current response, the impedance value and the phase shift can be determined. There are essentially two common impedance techniques, which enable us to get information about the capacitive behavior of a system. Either the impedance spectrum for a certain range of frequencies is measured (usually under potentiostatic conditions) or one particular frequency is chosen and the impedance is measured at constant frequency in dependence on the applied potential. Using the latter technique, the capacitance of the spacecharge layer can be calculated from the imaginary part of measured impedance:

$$
C_{\mathrm{sc}}=\frac{-i}{2 \pi f Z_{i m}},
$$

where $Z_{i m}$ denotes the imaginary part of impedance, $i$ is imaginary unit, and $f$ is the frequency of $a c$-voltage signal. For determination of $C_{\mathrm{sc}}$, a relatively high frequency is usually chosen and a simple equivalent circuit (neglecting the capacitive contribution of other elements) is employed for the interpretation of measured data.

From the resulting Mott-Schottky plot $\left(C_{S C}{ }^{-2}\right.$ versus $E$; see Figure 6), the flatband potential $E_{\mathrm{FB}}$ and the doping density $N_{\mathrm{D}}$ can be now obtained as the intercept with the $x$-axis and from the slope of the linear part. The value of the flatband potential from capacitance measurements on singlecrystal anatase is reported to be $-0.16 \mathrm{~V}$ versus $\mathrm{NHE}(\mathrm{pH} 0)$ with a Nernstian behavior exhibiting a shift of $-0.06 \mathrm{~V} / \mathrm{pH}$ unit [172]. However, it should be noted that the impedance response of the probed system often contains all contributions of the experimental setup, including back contact capacitance, sample resistance, electrolyte resistance, capacitance and resistance of Helmholtz layer and of surface states, which sometimes causes non-ideal behavior and makes it difficult to obtain reliable values of $E_{\mathrm{FB}}$ (see Figure 6) when using highly simplified equivalent circuits as in Figure 4(d). 


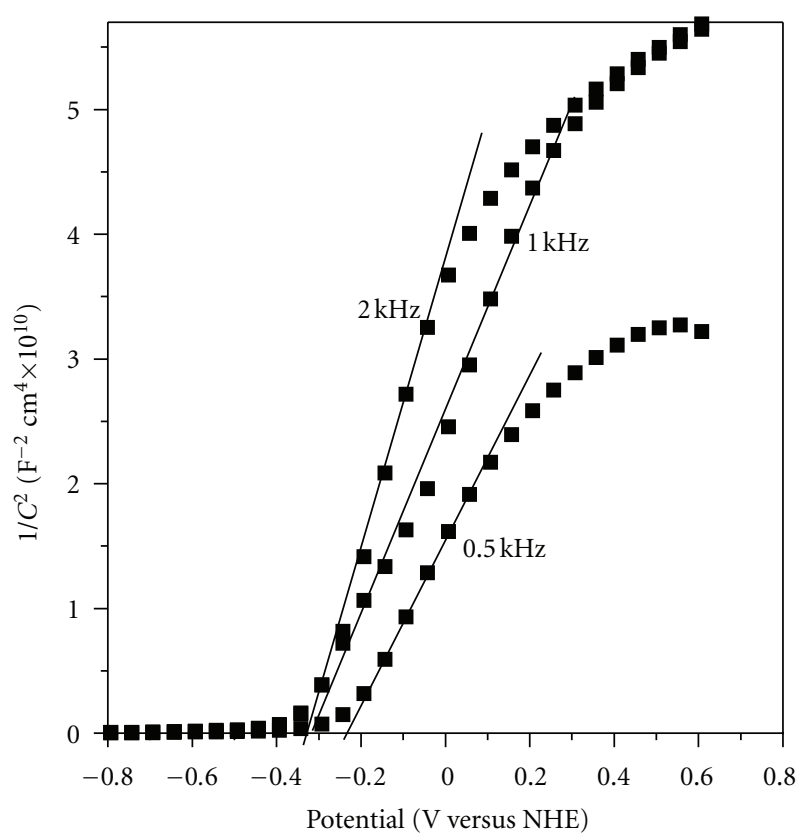

FIGURE 6: Mott-Schottky plots measured in $\mathrm{LiClO}_{4}(0.1 \mathrm{M}$; pH 6) electrolyte at three different frequencies on compact anodic $\mathrm{TiO}_{2}$ layers. The frequency dispersion is a frequent phenomenon related to the nonideality of the semiconductor.

\subsection{Photocurrent Onset Measurements. Another common} method for the determination of the position of the conduction band edge is a measurement of the potential dependence of photocurrent. The principle of photocurrent generation is explained in Figure 7. If a compact n-type semiconductor (like, e.g., a dense anodic $\mathrm{TiO}_{2}$ film on $\mathrm{Ti}$ ) immersed in the electrolyte under depletion conditions is irradiated with light of higher energy than that of its bandgap, electronhole pairs are generated and separated in the potential gradient of the space-charge layer (Figure 7(a)). In the case of an n-type semiconductor, this potential gradient drives photogenerated holes toward the semiconductor/electrolyte interface and electrons toward the interior of the electrode and from there to the electrical connection to the external circuit. Accordingly, anodic (positive) photocurrents are typically observed at $\mathrm{TiO}_{2}$ photoelectrodes. Obviously, if we sweep the potential of the photoelectrode in cathodic direction (upwards on the potential scale), the band bending will be less and less pronounced. The diminished potential gradient and thickness of the space-charge layer will lead to enhanced recombination of photogenerated charges, which will, in turn, lead to constant decrease of photocurrents during the cathodic potential sweep. Finally, at the flatband potential, the photocurrent should disappear totally [184]. Hence, this so-called "photocurrent onset" potential can be considered to coincide with the flatband potential and to merge practically with the conduction band edge.

Interestingly, similar principle applies also in case of nanocrystalline porous electrodes, in which the photogenerated charge separation is not controlled by the potential gradient over the space-charge region since the crystallite size is too small to support an effective depletion layer [158, 159].
Here, the photocurrent is determined by the efficiency of photogenerated electron/hole transfer at the semiconductor/electrolyte and semiconductor/substrate interface [160163]. This is schematically illustrated in Figure 7(b) which shows the mechanism of photocurrent generation at $\mathrm{TiO}_{2}$ particles deposited on the conductive glass substrate (e.g., ITO). Assuming the presence of suitable redox species in the electrolyte, photogenerated holes immediately react with these at the surface of the particles. The photogenerated electrons can be transferred to the underlying conductive glass substrate, assuming that the Fermi level of the conductive glass is positive enough. Hence again, by moving the Fermi level of the ITO electrode cathodically, we should observe the disappearance of photocurrents when the potential of the underlying electrode (the Fermi level of ITO) reaches the quasi-Fermi level of $\mathrm{TiO}_{2}$ particles, that is, their conduction band edge. In order to avoid scavenging of photogenerated electrons by oxygen dissolved in the solution, the electrolyte should be deaerated by purging with an inert gas prior to the measurement. Figure 7(c) shows a typical photovoltammogram recorded under interrupted illumination on a dense compact $\mathrm{TiO}_{2}$ electrode during the cathodic sweep. It should be noted that the absolute values of $E_{C}$ obtained are sometimes anodically shifted since the recombination becomes practically complete already at potentials relatively far $(0.1-0.3 \mathrm{~V})$ from the conduction band edge. Nevertheless, this method provides valuable information on shifts of $E_{\mathrm{C}}$, particularly when a direct comparison can be drawn from measurements on different samples under otherwise identical conditions.

3.3. Open-Circuit Photovoltage Measurements. Apart from the capacitance measurements and the photocurrent onset determination, the value of $E_{\mathrm{FB}}$ can be also determined from the dependence of the electrode open-circuit potential $\left(E_{\mathrm{OC}}\right)$ on the illumination intensity (Figure 8). Under open-circuit conditions, the photogenerated holes can accumulate at the surface, which with increasing light intensity lowers the barrier $U_{\mathrm{S}}$ (see Figure 3) for electrons until the electrons can reach the surface at the same rate as holes. At the same time, the quasi-Fermi level (measured as $E_{\mathrm{OC}}$ ) rises because of the higher occupancy of the conduction band. Accordingly, at sufficiently high-intensity, $E_{\mathrm{OC}}$ becomes constant and this value is very close to the potential of the conduction band edge [80, 125, 185-187]. In order to avoid reaction of photogenerated electrons with oxygen in the electrolyte, which would decrease the photovoltage, it is necessary to purge the solution with inert gas.

Figures 9(a), 9(b), and 9(c) show $E_{\mathrm{OC}}$ versus relative light intensity plots measured for a compact $\mathrm{TiO}_{2}$ film at different $\mathrm{pH}$ values. It is seen that $E_{\mathrm{OC}}$ becomes independent of intensity when the latter exceeds relative values of $90 \%$. The $E_{\mathrm{FB}}$ values plotted in Figure 9(d) show a nearly Nernstian linear dependence on $\mathrm{pH}$ with $E_{\mathrm{FB}}=(-0.17 \pm 0.02)-0.054(\mathrm{pH}) \mathrm{V}$ versus NHE, in agreement with values reported for anatase $\mathrm{TiO}_{2}$ [172]. Interestingly, the open-circuit photovoltage method yields reliable results also in case of nanocrystalline photoelectrodes [188, 189]. Under high-intensity illumination, the electrons accumulating in the conduction band and 


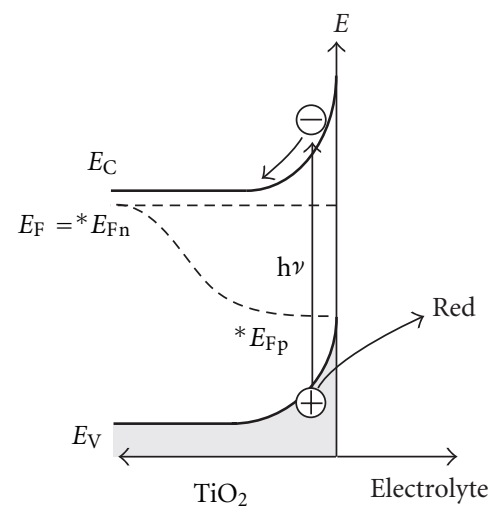

(a)

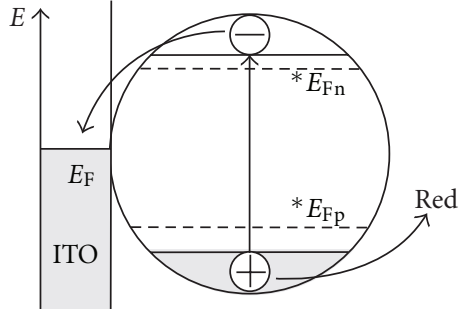

(b)

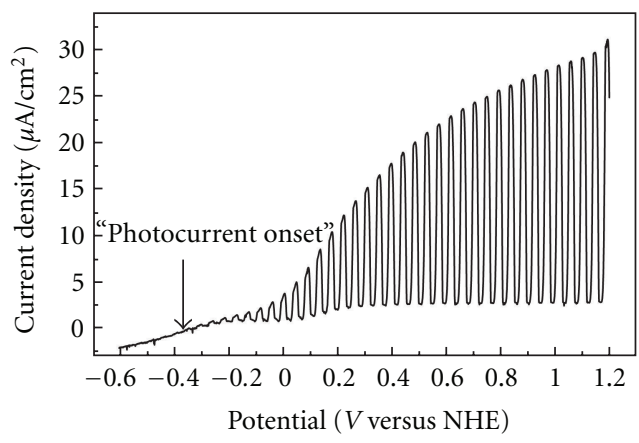

(c)

FIGURE 7: Schematic representation of the mechanism of photocurrent generation at a compact (a) and nanocrystalline (b) $\mathrm{TiO}_{2}$ electrode. (c) Photovoltammogram under interrupted illumination for a compact $\mathrm{TiO}_{2}$ electrode (dense anodic layer) recorded in $\mathrm{LiClO}_{4}(0.1 \mathrm{M}$; $\mathrm{pH}$ 6) electrolyte in the cathodic direction with the sweep rate of $2 \mathrm{mV} / \mathrm{s}$. The incident light wavelength was $350 \mathrm{~nm}$.
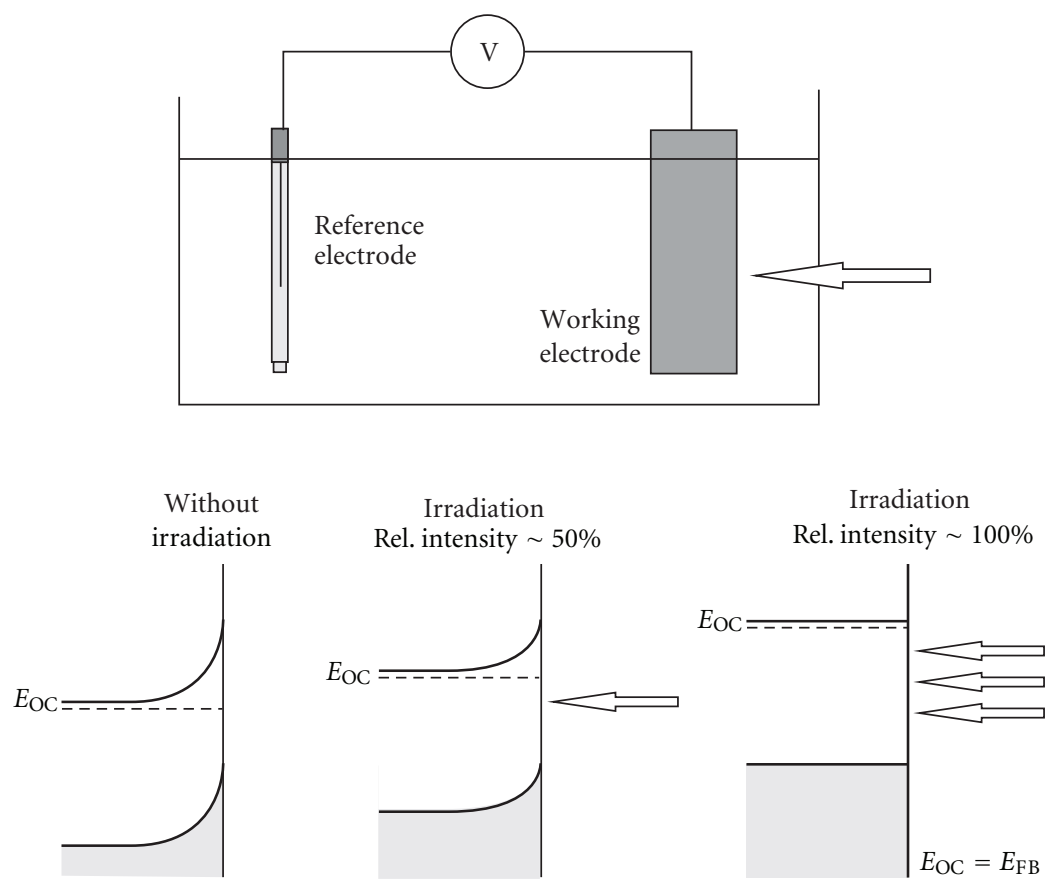

FIGURE 8: Schematic view of the flatband potential determination as the limiting value of the open-circuit potential ( $\left.E_{\mathrm{OC}}\right)$ under high relative irradiation intensity.

traps right bellow the conduction band edge cause the Fermi level of the conductive glass substrate to shift to the vicinity of $E_{\mathrm{C}}$ of $\mathrm{TiO}_{2}$. It is again emphasized that intense purging with inert gas is absolutely necessary in order to avoid scavenging of photogenerated electrons by oxygen dissolved in solution.

3.4. Spectroelectrochemical Measurements on Transparent Films. The fact that many nanocrystalline films are transparent offers the possibility to determine the position of the conduction band edges using the spectroelectrochemical method of Fitzmaurice et al. [190-192]. The principle of this method is schematically depicted in Figure 10. The Fermi level of ITO, $E_{\mathrm{F}}$ (ITO), can be controlled by applied potential, whereas the position of the conduction band edge of the transparent nanocrystalline $\mathrm{TiO}_{2}, E_{\mathrm{C}}\left(\mathrm{TiO}_{2}\right)$, depends only on the $\mathrm{pH}$ of the solution. At a constant $\mathrm{pH}$, applying potentials more negative than $E_{\mathrm{C}}\left(\mathrm{TiO}_{2}\right)$ leads to injection of electrons from ITO into the conduction band of $\mathrm{TiO}_{2}$ (Figure 10(b)). During injection of electrons into the conduction band, the $\mathrm{TiO}_{2}$ nanoparticles are not at thermodynamic equilibrium anymore; the Fermi level of $\mathrm{TiO}_{2}$ is therefore properly designated as a quasi-Fermi level, ${ }^{*} E_{\mathrm{Fn}}$, and practically merges with the conduction band edge, $E_{\mathrm{C}}$. 


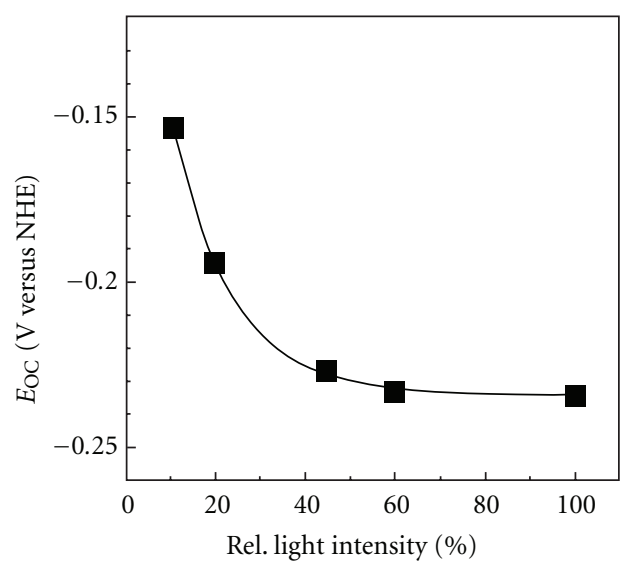

(a)

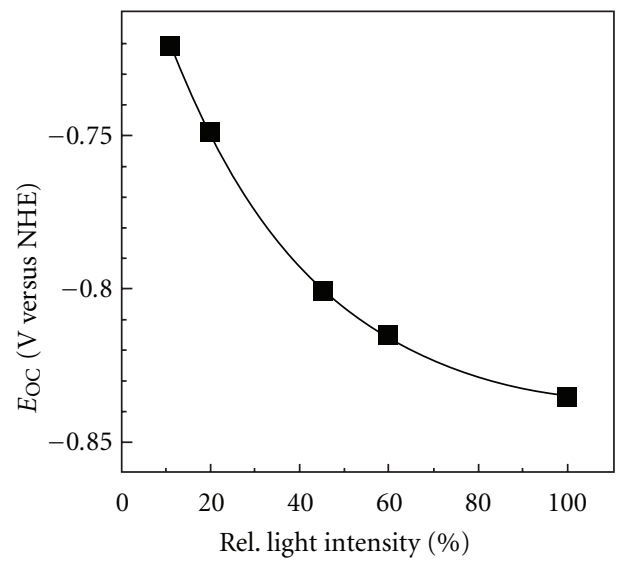

(c)

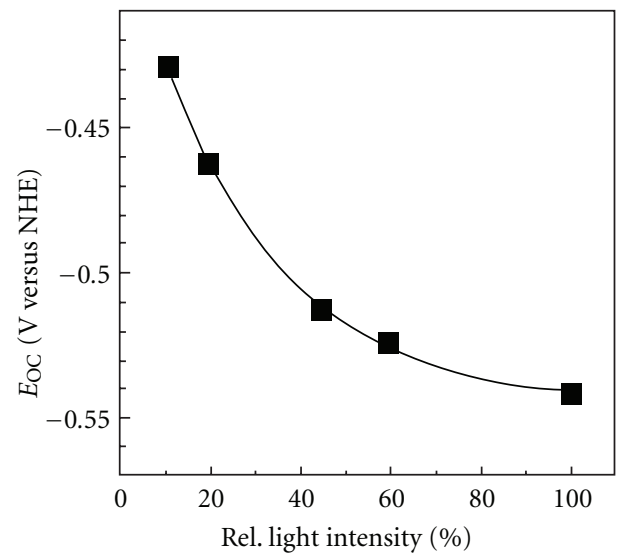

(b)

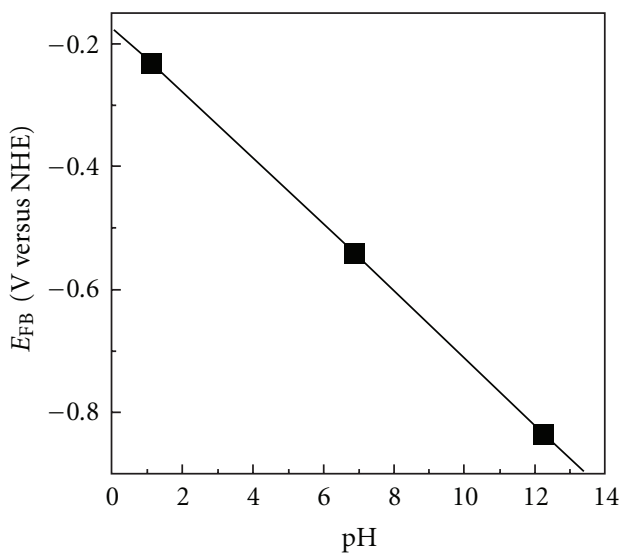

(d)

FIGURE 9: Dependence of the open-circuit potential $\left(E_{\mathrm{OC}}\right)$ on illumination intensity measured in (a) $\mathrm{HCl}(0.1 \mathrm{M} ; \mathrm{pH}=1.1),(\mathrm{b}) \mathrm{NaCl}(0.1 \mathrm{M}$; $\mathrm{pH}=6.9)$, and $(\mathrm{c}) \mathrm{NaOH}(0.1 \mathrm{M} ; \mathrm{pH}=12.3)$. (d) $\mathrm{pH}$ dependence of flatband potential $\left(E_{\mathrm{FB}}\right)$. The electrolyte was degassed by intense bubbling with nitrogen.

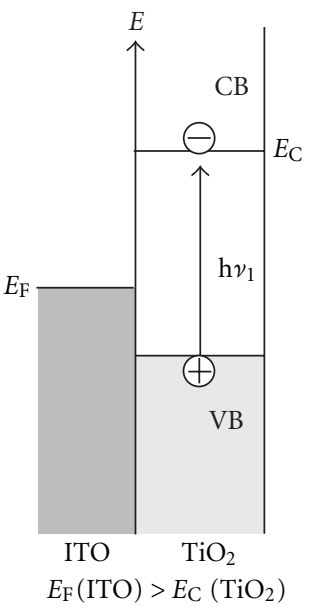

(a)

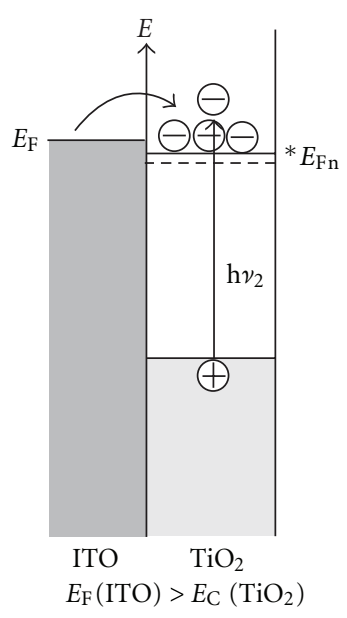

(b)

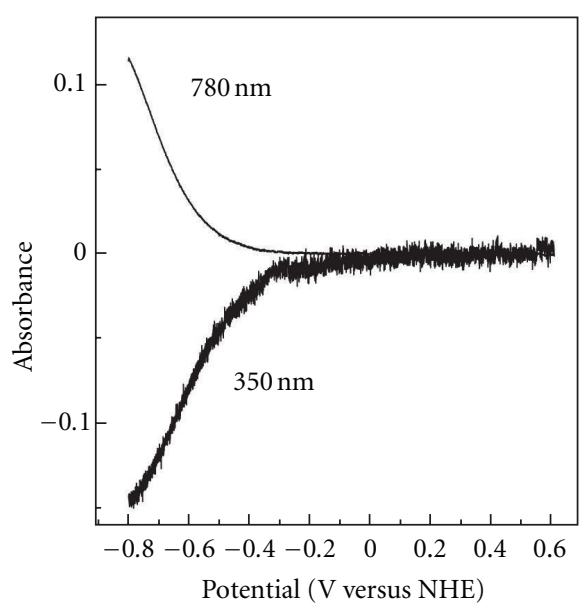

(c)

FIGURE 10: Schematic view of the principle of spectroelectrochemical determination of the quasi-Fermi level of nanocrystalline $\mathrm{TiO}_{2}(\mathrm{a}, \mathrm{b})$; for details, see the text. (c) Absorbance changes of a transparent $\mathrm{TiO}_{2}$ film at two different wavelengths recorded during a cathodic potential sweep in a deaerated $\mathrm{LiClO}_{4}(0.1 \mathrm{M})$ solution acidified to $\mathrm{pH} 2.9$. 


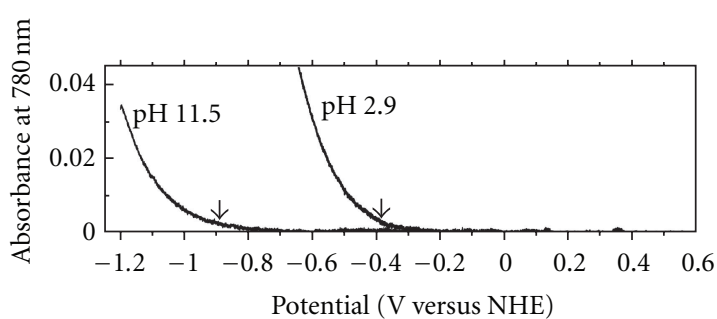

(a)

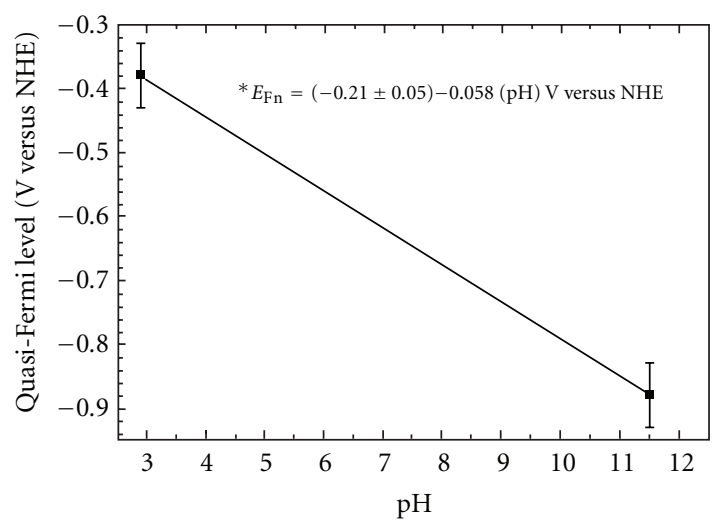

(b)

Figure 11: (a) Absorbance changes (at $780 \mathrm{~nm}$ ) of a transparent nanocrystalline $\mathrm{TiO}_{2}$ film recorded during a cathodic potential sweep in a deaerated $\mathrm{LiClO}_{4}(0.1 \mathrm{M})$ solution with adjusted $\mathrm{pH}$. The arrows indicate potentials at which the values of quasi-Fermi level were read off. (b) $\mathrm{pH}$ dependence of quasi-Fermi levels of a transparent nanocrystalline $\mathrm{TiO}_{2}$ film. Measurements were performed outside the neutral $\mathrm{pH}$ range in order to avoid $\mathrm{pH}$ fluctuations due to reduction of protons [206].

The occupation of states near the conduction band edge results in a shift to higher energies of the bandgap absorption edge (i.e., $h v_{2}>h \nu_{1}$ in Figures 10(a) and 10(b)) - the socalled Burstein-Moss shift $[193,194]$. From the spectroscopic point of view, this has two consequences. First, at potentials more negative than $E_{\mathrm{C}}\left(\mathrm{TiO}_{2}\right)$, the difference in absorbance at wavelengths lower than the typical absorption band edge (e.g., at $350 \mathrm{~nm}$ ) becomes negative. Second, the absorbance at $780 \mathrm{~nm}$ increases due to the intraband transitions of free electrons in the conduction band (Figure 10(c)) [190, 191, 195].

In this context, it should be noted that the nanocrystalline $\mathrm{TiO}_{2}$ has often a high density of electron traps that are distributed exponentially in the bandgap below the conduction band edge [196-200]. These traps can be obviously filled at potentials slightly more positive than $E_{C}$ and can also contribute to absorbance changes. This means that in practice it might be difficult to discern where exactly the rise in absorbance coincides with the potential of the conduction band edge. Figure 11(a) shows the absorbance changes at $\lambda=780 \mathrm{~nm}$ of a transparent nanocrystalline $\mathrm{TiO}_{2}$ film at two different $\mathrm{pH}$ values. The potentials of ${ }^{*} E_{\mathrm{Fn}}$ were in this case, somewhat arbitrarily, read off at points where the absorbance change was approximately 0.005 . The ${ }^{*} E_{\mathrm{Fn}}$ values (which coincide with the $E_{\mathrm{C}}$ values) plotted in Figure 11(b) show a nearly Nernstian linear dependence on $\mathrm{pH}$ with ${ }^{*} E_{\mathrm{Fn}}=$ $(-0.21 \pm 0.05)-0.058(\mathrm{pH}) \mathrm{V}$ versus NHE.

3.5. Quasi-Fermi Level Measurements on $\mathrm{TiO}_{2}$ Powder Suspensions. In the field of heterogeneous photocatalysis, $\mathrm{TiO}_{2}-$ based materials are often employed in the form of nanocrystalline powders. The quasi-Fermi level of electrons, ${ }^{*} E_{\mathrm{Fn}}$, can be in case of powder suspensions determined by the method of Roy et al. [29, 201] that draws on a similar method introduced previously by Bard et al. [202-204] In Roy's method, the $\mathrm{pH}$ dependence of the potential of a platinum electrode immersed in an irradiated suspension of a semiconductor powder (Figure 12) is recorded in the presence of an electron acceptor with $\mathrm{pH}$-independent reduction potential. As an electron acceptor, $\mathrm{MV}^{2+}$ (methyl viologen; 1,1'-dimethyl4,4' -bipyridinium dichloride; $E_{\mathrm{MV}^{2+/+}}=-0.45 \mathrm{~V}$ versus NHE) [130] is typically used (Figure 12(b)).

The principle of the method is depicted in Figure 13. At the beginning of the measurement, the $\mathrm{pH}$ of the solution is very low and the electrons generated in the conduction band do not have enough reducing power to reduce $\mathrm{MV}^{2+}$ (Figure 13(a)). Upon increasing the $\mathrm{pH}$ of the solution, the band edges of $\mathrm{TiO}_{2}$ shift to more negative potentials (see above Section 2.2), which makes at some point the electron transfer to $\mathrm{MV}^{2+}$ in the electrolyte possible (Figure 13(b)). The platinum electrode serves as a simple redox electrode in this case, and its potential shifts more negative with the increasing concentration of the reduced form of methyl viologen $\left(\mathrm{MV}^{+\bullet}\right)$ in the solution. The inflection point $\left(\mathrm{pH}_{0}\right)$ of the potential-pH curve (Figure 12(c)) determines the $\mathrm{pH}$ value at which ${ }^{*} E_{\mathrm{Fn}}$ coincides with $E_{\mathrm{MV}^{2+/+\bullet} \text {. Assuming }}$ Nernstian shift of band edges $(0.059 \mathrm{~V} / \mathrm{pH}$ unit) [125],

$$
{ }^{*} E_{\mathrm{Fn}}=E_{\mathrm{MV}^{2+/+} \bullet}+0.059\left(\mathrm{pH}_{0}-\mathrm{pH}\right) \text {. }
$$

Using this procedure, ${ }^{*} E_{\mathrm{Fn}}$ at $\mathrm{pH}=7$ of anatase $\mathrm{TiO}_{2}$ powder (Hombikat UV 100) was determined as $-0.60 \pm 0.02 \mathrm{~V}$ versus NHE, which is in a very good agreement with reported values for single-crystal anatase $(-0.58 \mathrm{~V}$ versus NHE) [172]. It should be also noted that efficient scavenging of photogenerated holes is essential during these measurements. In some cases-on doped or surface-modified $\mathrm{TiO}_{2}$ samples, for example_-an additional hole scavenger must be added in order to avoid severe recombination. Such a scavenger should be very easily oxidizable (e.g., iodide), and at the same time it should not produce strongly reducing radicals upon onehole oxidation (e.g., ethanol, isopropanol) since these are also able to reduce $\mathrm{MV}^{2+}$, which would falsify the resulting values of ${ }^{*} E_{\mathrm{Fn}}[205]$.

\section{Conclusions}

$\mathrm{TiO}_{2}$ nanomaterials play a key role in the development of various kinds of photochemical systems and devices, particularly in the field of heterogeneous photocatalysis and photoelectrochemistry. In the last years, we have witnessed a real boom of diverse strategies for fabrication of new types of $\mathrm{TiO}_{2}$-based materials showing an extreme variety in terms of 


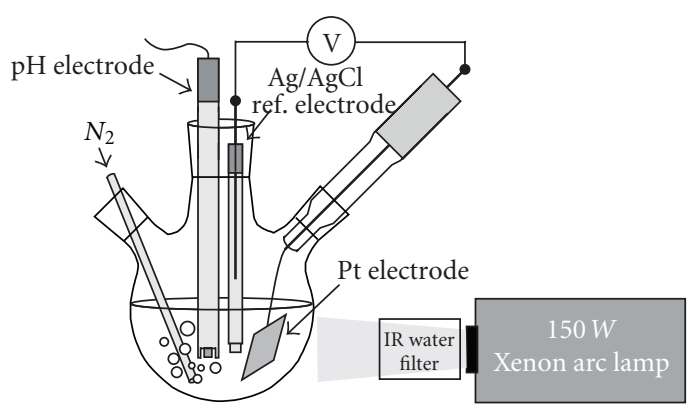

(a)

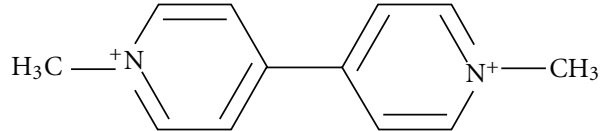

(b)

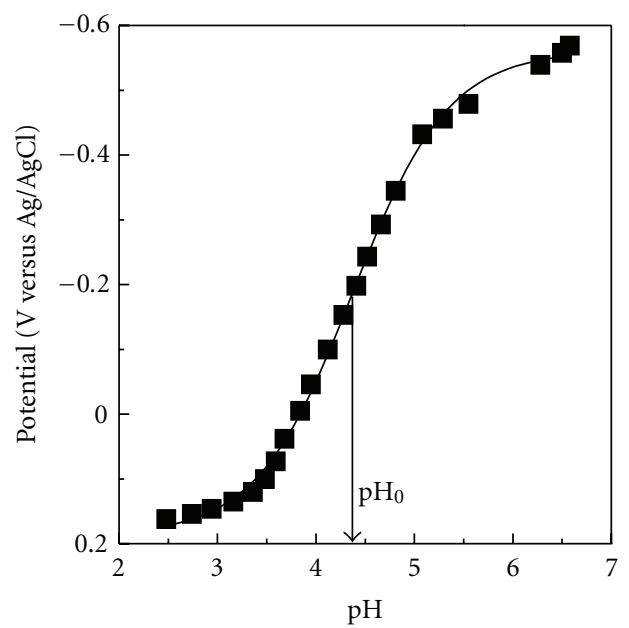

(c)

FIgURE 12: (a) Schematic view of the experimental setup for the determination of quasi-Fermi level for electrons using the method of Roy. A $60 \mathrm{~mL}$ solution of $\mathrm{KNO}_{3}(0.1 \mathrm{M})$ with a small amount of $\mathrm{MV}^{2+}$ is bubbled through with nitrogen in order to avoid the reoxidation of $\mathrm{MV}^{+} \cdot$ by dissolved oxygen. (b) Structure of $\mathrm{MV}^{2+}$. (c) Determination of the value of $\mathrm{pH}_{0}$ from a typical potential versus $\mathrm{pH}$ curve.

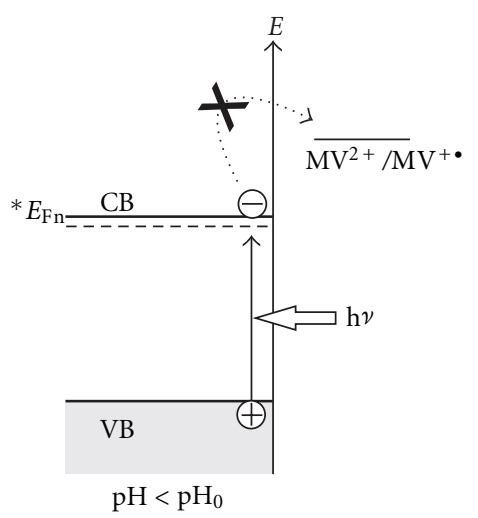

(a)

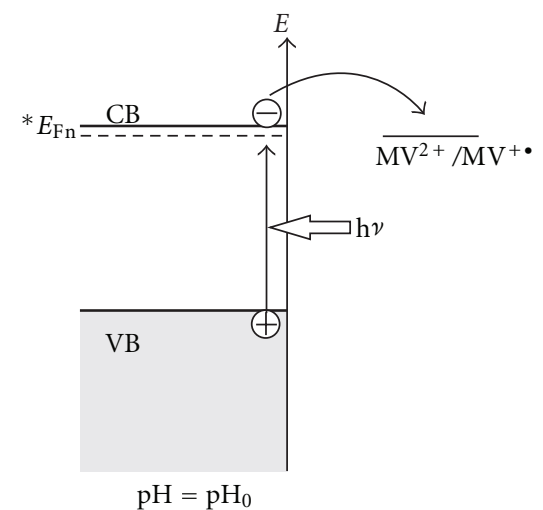

(b)

FIGURE 13: Schematic view of the principle of the determination of ${ }^{*} E_{\mathrm{Fn}}$. Upon increasing the $\mathrm{pH}$ of the solution, the band edges of a semiconductor shift to more negative potentials. At $\mathrm{pH}=\mathrm{pH}_{0}$, the value of ${ }^{*} E_{\mathrm{Fn}}$ matches the reduction potential of a $\mathrm{pH}$-independent redox species in the electrolyte $\left(\mathrm{MV}^{2+}\right)$.

composition, morphology, and surface properties. Although the knowledge of the position of the band edges on the potential scale is a crucial prerequisite for understanding the photoactivity of the system and for further optimization of its performance, it has been in recent years typically only rarely directly experimentally addressed. In this paper it has been shown that in case of $\mathrm{TiO}_{2}$ the general strategy for band edges determination usually consists in the measurement of the flatband potential and/or the quasi-Fermi level of electrons. Apart from "classical" approaches (capacitance 
measurements) developed in the field of semiconductor physics for well-defined samples in the form of single crystals, several novel techniques have been developed recently. These are particularly important since they are also suitable for measurements on non-ideal nanostructured, porous, and particulate materials, which represent the majority of currently newly developed materials. The methods discussed above included elaborate photoelectrochemical and spectroelectrochemical methods applicable on compact and nanocrystalline thin films, as well as on powder suspensions. Obviously, in case of many systems, a combination of several methods will give a more solid and complete assessment of the energetics at the solid/solution interface. It is hoped that this paper will serve as a useful resource for many scientists working in the field of photoactive nanomaterials and as an impetus for the development of further methods that will allow for better understanding and improvement of the photoactivity of photochemical systems and devices.

\section{Acknowledgments}

The financial support by the MIWFT-NRW within the project "Anorganische Nanomaterialien für Anwendungen in der Photokatalyse: Wasseraufbereitung und Wasserstoffgewinnung" and the support by the Center for Electrochemical Sciences (CES) are gratefully acknowledged. The company Sachtleben Chemie is acknowledged for providing a free sample of Hombikat UV 100.

\section{References}

[1] C. Renz, "Photo-reactions of the oxides of titanium, cerium, and the earth-acids," Helvetica Chimica Acta, vol. 4, pp. 961968, 1921.

[2] G. G. Rao and N. R. Dhar, "Photosensitized oxidation of ammonia and ammonium salts and the problem of nitrification in soils," Soil Science, vol. 31, pp. 379-384, 1931.

[3] N. R. Dhar and S. K. Mukherjee, "Photosynthesis of amino acids in vitro," Nature, vol. 134, no. 3387, p. 499, 1934.

[4] A. A. Krasnovskii and V. S. Kiselev, "A method for testing the activity of titanium dioxide in paint films," Tekh. Okraski, no. 3, pp. 26-27, 1940.

[5] C. F. Goodeve and J. A. Kitchener, "Photosensitisation by titanium dioxide," Transactions of the Faraday Society, vol. 34, pp. 570-579, 1938.

[6] A. E. Jacobsen, "Titanium dioxide pigments. Correlation between photochemical reactivity and chalking," Journal of Industrial and Engineering Chemistry, vol. 41, pp. 523-526, 1949.

[7] A. A. Krasnovskii and T. N. Gurevich, "Relation between atmospheric stability of pigmented paint films and the pigment-photosensitized formation of peroxide compounds,", Doklady Akademii Nauk SSSR, vol. 74, pp. 569-572, 1950.

[8] A. A. Krasnovskii and T. N. Gurevich, "Photocatalytic action of some metal oxides," Doklady Akademii Nauk SSSR, vol. 75, pp. 715-718, 1950.

[9] A. Fujishima and K. Honda, "Photosensitive electrode reactions. III. Electrochemical evidence for the mechanism of the primary stage of photosynthesis," Bulletin of the Chemical Society of Japan, vol. 44, no. 4, pp. 1148-1150, 1971.
[10] A. Fujishima and K. Honda, "Electrochemical photolysis of water at a semiconductor electrode," Nature, vol. 238, no. 5358, pp. 37-38, 1972.

[11] A. Fujishima, K. Honda, and S. Kikuchi, "Photochemical reactions of semiconductors. I. Photosensitized electrolytic oxidation on semiconducting n-type $\mathrm{TiO}_{2}$ electrode," Kogyo Kagaku Zasshi, vol. 72, no. 1, pp. 108-113, 1969.

[12] M. S. Wrighton, P. T. Wolczanski, and A. B. Ellis, "Photoelectrolysis of water by irradiation of platinized n-type semiconducting metal oxides," Journal of Solid State Chemistry, vol. 22, no. 1, pp. 17-29, 1977.

[13] M. Sharon and S. Licht, "Solar photoelectrochemical generation of hydrogen fuel," in Encyclopedia of Electrochemistry, S. Licht, Ed., vol. 6, pp. 346-357, Wiley-VCH, Weinheim, Germany, 2003.

[14] K. Rajeshwar, "Hydrogen generation at irradiated oxide semiconductor-solution interfaces," Journal of Applied Electrochemistry, vol. 37, no. 7, pp. 765-787, 2007.

[15] X. Chen, S. Shen, L. Guo, and S. S. Mao, "Semiconductorbased photocatalytic hydrogen generation," Chemical Reviews, vol. 110, no. 11, pp. 6503-6570, 2010.

[16] Z. Chen, T. F. Jaramillo, T. G. Deutsch et al., "Accelerating materials development for photoelectrochemical hydrogen production: standards for methods, definitions, and reporting protocols," Journal of Materials Research, vol. 25, no. 1, pp. 3-16, 2010.

[17] M. R. Hoffmann, S. T. Martin, W. Choi, and D. W. Bahnemann, "Environmental applications of semiconductor photocatalysis," Chemical Reviews, vol. 95, no. 1, pp. 69-96, 1995.

[18] A. Fujishima, T. N. Rao, and D. A. Tryk, "Titanium dioxide photocatalysis," Journal of Photochemistry and Photobiology C, vol. 1, no. 1, pp. 1-21, 2000.

[19] D. A. Tryk, A. Fujishima, and K. Honda, "Recent topics in photoelectrochemistry: achievements and future prospects," Electrochimica Acta, vol. 45, no. 15-16, pp. 2363-2376, 2000.

[20] O. Carp, C. L. Huisman, and A. Reller, "Photoinduced reactivity of titanium dioxide," Progress in Solid State Chemistry, vol. 32, no. 1-2, pp. 33-177, 2004.

[21] A. L. Linsebigler, G. Lu, and J. T. Yates Jr., "Photocatalysis on $\mathrm{TiO}_{2}$ surfaces: principles, mechanisms, and selected results," Chemical Reviews, vol. 95, no. 3, pp. 735-758, 1995.

[22] T. L. Thompson and J. T. Yates Jr., " $\mathrm{TiO}_{2}$-based photocatalysis: surface defects, oxygen and charge transfer," Topics in $\mathrm{Ca}$ talysis, vol. 35, no. 3-4, pp. 197-210, 2005.

[23] A. Fujishima, X. Zhang, and D. A. Tryk, " $\mathrm{TiO}_{2}$ photocatalysis and related surface phenomena," Surface Science Reports, vol. 63, no. 12, pp. 515-582, 2008.

[24] B. Ohtani, "Preparing articles on photocatalysis-beyond the illusions, misconceptions, and speculation," Chemistry Letters, vol. 37, no. 3, pp. 217-229, 2008.

[25] B. Ohtani, "Photocatalysis A to Z-What we know and what we do not know in a scientific sense," Journal of Photochemistry and Photobiology C, vol. 11, no. 4, pp. 157-178, 2011.

[26] S. N. Frank and A. J. Bard, "Heterogeneous photocatalytic oxidation of cyanide ion in aqueous solutions at $\mathrm{TiO}_{2}$ powder," Journal of the American Chemical Society, vol. 99, no. 1, pp. 303-304, 1977.

[27] S. N. Frank and A. J. Bard, "Heterogeneous photocatalytic oxidation of cyanide and sulfite in aqueous solutions at semiconductor powders," Journal of Physical Chemistry, vol. 81, no. 15, pp. 1484-1488, 1977.

[28] S. Sakthivel, M. Janczarek, and H. Kisch, "Visible light activity and photoelectrochemical properties of nitrogen-doped 
$\mathrm{TiO}_{2}$," Journal of Physical Chemistry B, vol. 108, no. 50, pp. 19384-19387, 2004.

[29] H. Kisch, G. Burgeth, and W. Macyk, "Visible light photocatalysis by a titania transition metal complex," Advances in Inorganic Chemistry, vol. 56, pp. 241-259, 2004.

[30] S. Sakthivel and H. Kisch, "Daylight photocatalysis by carbon-modified titanium dioxide," Angewandte ChemieInternational Edition, vol. 42, no. 40, pp. 4908-4911, 2003.

[31] S. Sakthivel and H. Kisch, "Photocatalytic and photoelectrochemical properties of nitrogen-doped titanium dioxide," ChemPhysChem, vol. 4, no. 5, pp. 487-490, 2003.

[32] W. Macyk, G. Burgeth, and H. Kisch, "Photoelectrochemical properties of platinum(IV) chloride surface modified $\mathrm{TiO}_{2}$," Photochemical and Photobiological Sciences, vol. 2, no. 3, pp. 322-328, 2003.

[33] G. Burgeth and H. Kisch, "Photocatalytic and photoelectrochemical properties ot titaniachloroplatinate(IV)," Coordination Chemistry Reviews, vol. 230, no. 1-2, pp. 41-47, 2002.

[34] H. Kisch and W. Macyk, "Visible-light photocatalysis by modified titania," ChemPhysChem, vol. 3, no. 5, pp. 399-400, 2002.

[35] C. Lettmann, K. Hildenbrand, H. Kisch, W. Macyk, and W. F. Maier, "Visible light photodegradation of 4-chlorophenol with a coke-containing titanium dioxide photocatalyst," Applied Catalysis B, vol. 32, no. 4, pp. 215-227, 2001.

[36] W. Macyk and H. Kisch, "Photosensitization of crystalline and amorphous titanium dioxide by platinum(IV) chloride surface complexes," Chemistry, vol. 7, no. 9, pp. 1862-1867, 2001.

[37] C. Chen, W. Ma, and J. Zhao, "Semiconductor-mediated photodegradation of pollutants under visible-light irradiation," Chemical Society Reviews, vol. 39, no. 11, pp. 42064219, 2010.

[38] D. Mitoraj, R. Beránek, and H. Kisch, "Mechanism of aerobic visible light formic acid oxidation catalyzed by poly(tri-striazine) modified titania," Photochemical and Photobiological Sciences, vol. 9, no. 1, pp. 31-38, 2010.

[39] D. Mitoraj and H. Kisch, "On the mechanism of ureainduced titania modification," Chemistry, vol. 16, no. 1, pp. 261-269, 2010.

[40] R. Wang, K. Hashimoto, A. Fujishima et al., "Light-induced amphiphilic surfaces," Nature, vol. 388, no. 6641, pp. 431432, 1997.

[41] R. Wang, K. Hashimoto, A. Fujishima et al., "Photogeneration of highly amphiphilic $\mathrm{TiO}_{2}$, , Advanced Materials, vol. 10, no. 2, pp. 135-138, 1998.

[42] R. Wang, N. Sakai, A. Fujishima, T. Watanabe, and K. Hashimoto, "Studies of surface wettability conversion on $\mathrm{TiO}_{2}$," Journal of Physical Chemistry B, vol. 103, no. 12, pp. 2188-2194, 1999.

[43] T. Zubkoy, D. Stahl, T. L. Thompson, D. Panayotov, O. Diwald, and J. T. Yates Jr., "Ultraviolet light-induced hydrophilicity effect on $\mathrm{TiO}_{2}(110)(1 \times 1)$. Dominant role of the photooxidation of adsorbed hydrocarbons causing wetting by water droplets," Journal of Physical Chemistry B, vol. 109, no. 32, pp. 15454-15462, 2005.

[44] B. Kraeutler and A. J. Bard, "Heterogeneous photocatalytic synthesis of methane from acetic acid-new Kolbe reaction pathway," Journal of the American Chemical Society, vol. 100, no. 7, pp. 2239-2240, 1978.

[45] P. Du, J. A. Moulijn, and G. Mul, "Selective photo(catalytic)oxidation of cyclohexane: effect of wavelength and $\mathrm{TiO}_{2}$ structure on product yields," Journal of Catalysis, vol. 238, no. 2, pp. 342-352, 2006.

[46] F. Parrino, A. Ramakrishnan, and H. Kisch, "Semiconductorphotocatalyzed sulfoxidation of alkanes," Angewandte Chemie-International Edition, vol. 47, no. 37, pp. 7107-7109, 2008.

[47] Q. Wang, M. Zhang, C. Chen, W. Ma, and J. Zhao, "Photocatalytic aerobic oxidation of alcohols on $\mathrm{TiO}_{2}$," Angewandte Chemie-International Edition, vol. 49, no. 43, pp. 79767979, 2010.

[48] S. I. Naya, A. Inoue, and H. Tada, "Self-assembled heterosupramolecular visible light photocatalyst consisting of gold nanoparticle-loaded titanium(IV) dioxide and surfactant," Journal of the American Chemical Society, vol. 132, no. 18, pp. 6292-6293, 2010.

[49] X. Lang, H. Ji, C. Chen, W. Ma, and J. Zhao, "Selective formation of imines by aerobic photocatalytic oxidation of amines on $\mathrm{TiO}_{2}$," Angewandte Chemie-International Edition, vol. 50, no. 17, pp. 3934-3937, 2011.

[50] H. Sakai, R. Baba, K. Hashimoto, Y. Kubota, and A. Fujishima, "Selective killing of a single cancerous T24 cell with $\mathrm{TiO}_{2}$ semiconducting microelectrode under irradiation," Chemistry Letters, no. 3, pp. 185-186, 1995.

[51] A. H. Sakai, R. X. Cai, T. Yoshioka, Y. Kubota, K. Hashimoto, and A. Fujishima, "Intracellular $\mathrm{Ca}^{2+}$ concentration change of T24 cell under irradiation in the presence of $\mathrm{TiO}_{2}$ ultrafine particles," Biochimica et Biophysica Acta, vol. 1201, no. 2, pp. 259-265, 1994.

[52] R. Cai, Y. Kubota, T. Shuin, H. Sakai, K. Hashimoto, and A. Fujishima, "Induction of cytotoxicity by photoexcited $\mathrm{TiO} 2$ particles," Cancer Research, vol. 52, no. 8, pp. 2346-2348, 1992.

[53] R. Cai, K. Hashimoto, Y. Kubota, and A. Fujishima, "Increment of photocatalytic killing of cancer cells using titanium dioxide with the aid of superoxide dismutase," Chemistry Letters, no. 3, pp. 427-430, 1992.

[54] R. Cai, K. Hashimoto, K. Itoh, Y. Kubota, and A. Fujishima, "Photokilling of malignant cells with ultrafine $\mathrm{TiO}_{2}$ powder," Bulletin of the Chemical Society of Japan, vol. 64, no. 4, pp. 1268-1273, 1991.

[55] H. Gerischer and H. Tributsch, "Electrochemical studies on the spectral sensitization of zinc oxide single crystals," Berichte der Bunsen-Gesellschaft, vol. 72, no. 3, pp. 437-445, 1968.

[56] H. Tributsch and H. Gerischer, "Electrochemical studies on the mechanism of sensitization and supersensitization of zinc oxide single crystals," Berichte der Bunsen-Gesellschaft, vol. 73, no. 3, pp. 251-260, 1969.

[57] H. Tributsch and H. Gerischer, "Use of semiconductor electrodes in the study of photochemical reactions," Berichte der Bunsen-Gesellschaft, vol. 73, no. 8-9, pp. 850-854, 1969.

[58] H. Tributsch, "Reaction of excited chlorophyll molecules at electrodes and in photosynthesis," Photochemistry and Photobiology, vol. 16, no. 4, pp. 261-269, 1972.

[59] H. Tributsch and M. Calvin, "Electrochemistry of excited molecules. Photoelectrochemical reactions of chlorophylls," Photochemistry and Photobiology, vol. 14, no. 2, pp. 95-112, 1971.

[60] M. Matsumura, S. Matsudaira, H. Tsubomura, M. Takata, and H. Yanagida, "Dye sensitization and surface structures of semiconductor electrodes," Industrial \& Engineering Chemistry Product Research and Development, vol. 19, no. 3, pp. 415-421, 1980. 
[61] J. Desilvestro, M. Grätzel, L. Kavan, J. Moser, and J. Augustynski, "Highly efficient sensitization of titanium dioxide," Journal of the American Chemical Society, vol. 107, no. 10, pp. 2988-2990, 1985.

[62] B. O’Regan and M. Grätzel, "A low-cost, high-efficiency solar cell based on dye-sensitized colloidal $\mathrm{TiO}_{2}$ films," Nature, vol. 353, no. 6346, pp. 737-740, 1991.

[63] M. Grätzel, "Photoelectrochemical cells," Nature, vol. 414, no. 6861, pp. 338-344, 2001.

[64] B. C. O'Regan and J. R. Durrant, "Kinetic and energetic paradigms for dyesensitized solar cells: moving from the ideal to the real," Accounts of Chemical Research, vol. 42, no. 11, pp. 1799-1808, 2009.

[65] L. Spanhel, H. Weller, and A. Henglein, "Photochemistry of semiconductor colloids. 22. Electron injection from illuminated CdS into attached $\mathrm{TiO}_{2}$ and $\mathrm{ZnO}$ particles," Journal of the American Chemical Society, vol. 109, no. 22, pp. 66326635, 1987.

[66] R. Vogel, P. Hoyer, and H. Weller, "Quantum-sized PbS, CdS, $\mathrm{Ag}_{2} \mathrm{~S}, \mathrm{Sb}_{2} \mathrm{~S}_{3}$, and $\mathrm{Bi}_{2} \mathrm{~S}_{3}$ particles as sensitizers for various nanoporous wide-bandgap semiconductors," Journal of Physical Chemistry, vol. 98, no. 12, pp. 3183-3188, 1994.

[67] A. J. Nozik, "Quantum dot solar cells," Physica E, vol. 14, no. 1-2, pp. 115-120, 2002.

[68] L. M. Peter, D. J. Riley, E. J. Tull, and K. G.U. Wijayantha, "Photosensitization of nanocrystalline $\mathrm{TiO}_{2}$ by self-assembled layers of CdS quantum dots," Chemical Communications, no. 10, pp. 1030-1031, 2002.

[69] P. V. Kamat, "Quantum dot solar cells. Semiconductor nanocrystals as light harvesters," Journal of Physical Chemistry C, vol. 112, no. 48, pp. 18737-18753, 2008.

[70] P. V. Kamat, K. Tvrdy, D. R. Baker, and J. G. Radich, "Beyond photovoltaics: semiconductor nanoarchitectures for liquidjunction solar cells," Chemical Reviews, vol. 110, no. 11, pp. 6664-6688, 2010.

[71] Y. Tian and T. Tatsuma, "Mechanisms and applications of plasmon-induced charge separation at $\mathrm{TiO}_{2}$ films loaded with gold nanoparticles," Journal of the American Chemical Society, vol. 127, no. 20, pp. 7632-7637, 2005.

[72] Z. Liu, W. Hou, P. Pavaskar, M. Aykol, and S. B. Cronin, "Plasmon resonant enhancement of photocatalytic water splitting under visible illumination," Nano Letters, vol. 11, no. 3, pp. 1111-1116, 2011.

[73] J. Tang, "Interaction between noble metal nanoparticles and light for contaminant decomposition," ChemSusChem, vol. 3, no. 7, pp. 800-801, 2010.

[74] Y. Nishijima, K. Ueno, Y. Yokota, K. Murakoshi, and H. Misawa, "Plasmon-assisted photocurrent generation from visible to near-infrared wavelength using a Au-nanorods/ $/ \mathrm{TiO}_{2}$," Journal of Physical Chemistry Letters, vol. 1, no. 13, pp. 20312036, 2010.

[75] S. I. Naya, A. Inoue, and H. Tada, "Visible-light activity enhancement of gold-nanoparticle-loaded titanium(IV) dioxide by preferential excitation of localized surface plasmon resonance," ChemPhysChem, vol. 12, no. 15, pp. 2719 2723, 2011.

[76] H. Kisch, L. Zang, C. Lange, W. F. Maier, C. Antonius, and D. Meissner, "Modified, amorphous titania-a hybrid semiconductor for detoxification and current generation by visible light," Angewandte Chemie_-International Edition, vol. 37, no. 21, pp. 3034-3036, 1998.

[77] E. Vrachnou, N. Vlachopoulos, and M. Grätzel, "Efficient visible light sensitization of $\mathrm{TiO}_{2}$ a by surface complexation with $\mathrm{Fe}(\mathrm{CN})_{6}^{4-}$," Journal of the Chemical Society, Chemical Communications, vol. 37, no. 12, pp. 868-870, 1987.

[78] M. Khoudiakov, A. R. Parise, and B. S. Brunschwig, "Interfacial electron transfer in $\mathrm{Fe}^{\mathrm{II}}(\mathrm{CN})_{6}^{4-}$ sensitized $\mathrm{TiO}_{2}$ nanoparticles: a study of direct charge injection by electroabsorption spectroscopy," Journal of the American Chemical Society, vol. 125, no. 15, pp. 4637-4642, 2003.

[79] W. Macyk, G. Stochel, and K. Szaciłowski, "Photosensitization and the photocurrent switching effect in nanocrystalline titanium dioxide functionalized with Iron(II) complexes: a comparative study," Chemistry, vol. 13, no. 20, pp. 56765687, 2007.

[80] R. Beranek and H. Kisch, "Surface-modified anodic $\mathrm{TiO}_{2}$ films for visible light photocurrent response," Electrochemistry Communications, vol. 9, no. 4, pp. 761-766, 2007.

[81] R. Beranek and H. Kisch, "Tuning the optical and photoelectrochemical properties of surface-modified $\mathrm{TiO}_{2}$," Photochemical and Photobiological Sciences, vol. 7, no. 1, pp. 40-48, 2007.

[82] R. Beranek, J. M. Macak, M. Gärtner, K. Meyer, and P. Schmuki, "Enhanced visible light photocurrent generation at surface-modified $\mathrm{TiO}_{2}$ nanotubes," Electrochimica Acta, vol. 54, no. 9, pp. 2640-2646, 2009.

[83] D. Mitoraj and H. Kisch, "The nature of nitrogen-modified titanium dioxide photocatalysts active in visible light," Angewandte Chemie-International Edition, vol. 47, no. 51, pp. 9975-9978, 2008.

[84] H. Irie, K. Kamiya, T. Shibanuma et al., "Visible lightsensitive $\mathrm{Cu}(\mathrm{II})$-grafted $\mathrm{TiO}_{2}$ photocatalysts: activities and X-ray absorption fine structure analyses," Journal of Physical Chemistry C, vol. 113, no. 24, pp. 10761-10766, 2009.

[85] H. Yu, H. Irie, Y. Shimodaira et al., "An efficient visiblelight-sensitive $\mathrm{Fe}(\mathrm{III})$-grafted $\mathrm{TiO}_{2}$ photocatalyst," Journal of Physical Chemistry C, vol. 114, no. 39, pp. 16481-16487, 2010.

[86] K. Palmisano, V. Augugliaro, A. Sclafani, and M. Schiavello, "Activity of chromium-ion-doped titania for the dinitrogen photoreduction to ammonia and for the phenol photodegradation," Journal of Physical Chemistry, vol. 92, no. 23, pp. 6710-6713, 1988.

[87] A. Di Paola, G. Marcì, L. Palmisano et al., "Preparation of polycrystalline $\mathrm{TiO}_{2}$ photocatalysts impregnated with various transition metal ions: characterization and photocatalytic activity for the degradation of 4-nitrophenol," Journal of Physical Chemistry B, vol. 106, no. 3, pp. 637-645, 2002.

[88] M. Anpo, "Use of visible light. Second-generation titanium oxide photocatalysts prepared by the application of an advanced metal ion-implantation method," Pure and Applied Chemistry, vol. 72, no. 9, pp. 1787-1792, 2000.

[89] S. U. M. Khan, M. Al-Shahry, and W. B. Ingler Jr., "Efficient photochemical water splitting by a chemically modified n$\mathrm{TiO}_{2}$," Science, vol. 297, no. 5590, pp. 2243-2245, 2002.

[90] T. Hirai, I. Tari, and J. Yamaura, "Titanium nitride oxide (TiN0.07O1.93) semiconductor electrodes for photoassisted oxidation of water," Bulletin of the Chemical Society of Japan, vol. 51, no. 10, pp. 3057-3058, 1978.

[91] S. Sato, "Photocatalytic activity of nitrogen oxide $\left(\mathrm{NO}_{x}\right)$ doped titanium dioxide in the visible light region," Chemical Physics Letters, vol. 123, no. 1-2, pp. 126-128, 1986.

[92] R. Asahi, T. Morikawa, T. Ohwaki, K. Aoki, and Y. Taga, "Visible-light photocatalysis in nitrogen-doped titanium oxides," Science, vol. 293, no. 5528, pp. 269-271, 2001. 
[93] A. Ghicov, J. M. Macak, H. Tsuchiya et al., " $\mathrm{TiO}_{2}$ nanotube layers: dose effects during nitrogen doping by ion implantation," Chemical Physics Letters, vol. 419, no. 4-6, pp. 426-429, 2006.

[94] T. Lindgren, J. M. Mwabora, E. Avandaño et al., "Photoelectrochemical and optical properties of nitrogen doped titanium dioxide films prepared by reactive DC magnetron sputtering," Journal of Physical Chemistry B, vol. 107, no. 24, pp. 5709-5716, 2003.

[95] H. Irie, Y. Watanabe, and K. Hashimoto, "Nitrogen-concentration dependence on photocatalytic activity of $\mathrm{TiO}_{2-\mathrm{x}} \mathrm{N}_{\mathrm{x}}$ powders," Journal of Physical Chemistry B, vol. 107, no. 23, pp. 5483-5486, 2003.

[96] C. Burda, Y. Lou, X. Chen, A. C. S. Samia, J. Stout, and J. L. Gole, "Enhanced nitrogen doping in $\mathrm{TiO}_{2}$ Nanoparticles," Nano Letters, vol. 3, no. 8, pp. 1049-1051, 2003.

[97] M. Sathish, B. Viswanathan, R. P. Viswanath, and C. S. Gopinath, "Synthesis, characterization, electronic structure, and photocatalytic activity of nitrogen-doped $\mathrm{TiO}_{2}$ nanocatalyst," Chemistry of Materials, vol. 17, no. 25, pp. 6349-6353, 2005.

[98] T. Umebayashi, T. Yamaki, H. Itoh, and K. Asai, "Band gap narrowing of titanium dioxide by sulfur doping," Applied Physics Letters, vol. 81, no. 3, p. 454, 2002.

[99] T. Ohno, "Preparation of visible light active S-doped $\mathrm{TiO}_{2}$ photocatalysts and their photocatalytic activities," Water Science and Technology, vol. 49, no. 4, pp. 159-163, 2004.

[100] M. Zheng, Y. Cui, X. Li, S. Liu, and Z. Tang, "Photoelectrochemical sensing of glucose based on quantum dot and enzyme nanocomposites," Journal of Electroanalytical Chemistry, vol. 656, no. 1-2, pp. 167-173, 2011.

[101] G. L. Wang, J. J. Xu, and H. Y. Chen, "Dopamine sensitized nanoporous $\mathrm{TiO}_{2}$ film on electrodes: photoelectrochemical sensing of NADH under visible irradiation," Biosensors and Bioelectronics, vol. 24, no. 8, pp. 2494-2498, 2009.

[102] K. Szaciłowski and W. Macyk, "Chemical switches and logic gates based on surface modified semiconductors," Comptes Rendus Chimie, vol. 9, no. 2, pp. 315-324, 2006.

[103] M. Hebda, G. Stochel, K. Szaciłowski, and W. Macyk, "Optoelectronic switches based on wide band gap semiconductors," Journal of Physical Chemistry B, vol. 110, no. 31, pp. 1527515283, 2006.

[104] K. Szaciłowski, W. Macyk, and G. Stochel, "Light-driven OR and XOR programmable chemical logic gates," Journal of the American Chemical Society, vol. 128, no. 14, pp. 4550-4551, 2006.

[105] L. F. O. Furtado, A. D. P. Alexiou, L. Gonçalves, H. E. Toma, and K. Araki, " $\mathrm{TiO}_{2}$-based light-driven XOR/INH logic gates," Angewandte Chemie-International Edition, vol. 45, no. 19, pp. 3143-3146, 2006.

[106] R. Beranek and H. Kisch, "A hybrid semiconductor electrode for wavelength-controlled switching of the photocurrent direction," Angewandte Chemie-International Edition, vol. 47, no. 7, pp. 1320-1322, 2008.

[107] H. Ming, Z. Ma, H. Huang et al., "Nanoporous $\mathrm{TiO}_{2}$ spheres with narrow pore size distribution and improved visible light photocatalytic abilities," Chemical Communications, vol. 47, no. 28, pp. 8025-8027, 2011.

[108] P. Roy, S. Berger, and P. Schmuki, " $\mathrm{TiO}_{2}$ nanotubes: synthesis and applications," Angewandte Chemie-International Edition, vol. 50, no. 13, pp. 2904-2939, 2011.

[109] C. A. Grimes and G. K. Mor, $\mathrm{TiO}_{2}$ Nanotube Arrays: Synthesis, Properties, and Applications, Springer, New York, NY, USA, 2009.
[110] W. P. Liao and J. J. Wu, "Wet chemical route to hierarchical $\mathrm{TiO}_{2}$ nanodendrite/ nanoparticle composite anodes for dyesensitized solar cells," Journal of Materials Chemistry, vol. 21, no. 25, pp. 9255-9262, 2011.

[111] D. Fattakhova-Rohlfing, M. Wark, T. Brezesinski, B. M. Smarsly, and J. Rathouský, "Highly organized mesoporous $\mathrm{TiO}_{2}$ films with controlled crystallinity: a Li-insertion study," Advanced Functional Materials, vol. 17, no. 1, pp. 123-132, 2007.

[112] J. M. Szeifert, D. Fattakhova-Rohlfing, D. Georgiadou et al., "Brick and mortar strategy for the formation of highly crystalline mesoporous titania films from nanocrystalline building blocks," Chemistry of Materials, vol. 21, no. 7, pp. 1260$1265,2009$.

[113] J. Pan, G. Liu, G. Q. Lu, and H. M. Cheng, "On the true photoreactivity order of $\{001\},\{010\}$, and $\{101\}$ facets of anatase $\mathrm{TiO}_{2}$ crystals," Angewandte Chemie-International Edition, vol. 50, no. 9, pp. 2133-2137, 2011.

[114] H. G. Yang, C. H. Sun, S. Z. Qiao et al., "Anatase $\mathrm{TiO}_{2}$ single crystals with a large percentage of reactive facets," Nature, vol. 453, no. 7195, pp. 638-641, 2008.

[115] J. I. L. Chen, E. Loso, N. Ebrahim, and G. A. Ozin, "Synergy of slow photon and chemically amplified photochemistry in platinum nanocluster-loaded inverse titania opals," Journal of the American Chemical Society, vol. 130, no. 16, pp. 54205421, 2008.

[116] J. I. L. Chen, G. Von Freymann, S. Y. Choi, V. Kitaev, and G. A. Ozin, "Amplified photochemistry with slow photons," Advanced Materials, vol. 18, no. 14, pp. 1915-1919, 2006.

[117] F. Sordello, C. Duca, V. Maurino, and C. Minero, "Photocatalytic metamaterials: $\mathrm{TiO}_{2}$ inverse opals," Chemical Communications, vol. 47, no. 21, pp. 6147-6149, 2011.

[118] I. Bannat, K. Wessels, T. Oekermann, J. Rathousky, D. Bahnemann, and M. Wark, "Improving the photocatalytic performance of mesoporous titania films by modification with gold nanostructures," Chemistry of Materials, vol. 21, no. 8, pp. 1645-1653, 2009.

[119] Q. Xiang, J. Yu, and M. Jaroniec, "Graphene-based semiconductor photocatalysts," Chemical Society Reviews, vol. 41, no. 2, pp. 782-796, 2012.

[120] I. V. Lightcap, T. H. Kosel, and P. V. Kamat, "Anchoring semiconductor and metal nanoparticles on a two-dimensional catalyst mat. storing and shuttling electrons with reduced graphene oxide," Nano Letters, vol. 10, no. 2, pp. 577-583, 2010.

[121] W. Fan, Q. Lai, Q. Zhang, and Y. Wang, "Nanocomposites of $\mathrm{TiO}_{2}$ and reduced graphene oxide as efficient photocatalysts for hydrogen evolution," Journal of Physical Chemistry C, vol. 115, no. 21, pp. 10694-10701, 2011.

[122] M. D. Archer and A. J. Nozik, Eds., Nanostructured and Photoelectrochemical Systems for Solar Photon Conversion, Imperial College Press, 2008.

[123] S. Trasatti, "The absolute electrode potential: an explanatory note. Recommendations 1986," Pure and Applied Chemistry, vol. 58, no. 7, pp. 955-966, 1986.

[124] V. Tripkovic, M. E. Björketun, E. Skúlason, and J. Rossmeisl, "Standard hydrogen electrode and potential of zero charge in density functional calculations," Physical Review B, vol. 84, no. 11, Article ID 115452, 2011.

[125] S. R. Morrison, Electrochemistry at Semiconductor and Oxidized Metal Electrodes, Plenum Press, New York, NY, USA, 1980.

[126] Y. V. Pleskov and Y. Y. Gurevich, Semiconductor Photoelectrochemistry, Plenum Press, New York, NY, USA, 1986. 
[127] M. X. Tan, P. E. Laibinis, S. T. Nguyen, J. M. Kesselman, C. E. Stanton, and N. S. Lewis, "Principles and applications of semiconductor photoelectrochemistry," Progress in Inorganic Chemistry, vol. 41, pp. 21-144, 1994.

[128] R. Memming, Semiconductor Electrochemistry, Wiley-VCH, Weinheim, Germany, 2001.

[129] K. Rajeshwar, "Fundamentals of semiconductor electrochemistry and photoelectrochemistry," in Semiconductor Electrodes and Photoelectrochemistry, S. Licht, Ed., vol. 6, pp. 1-57, Wiley-VCH, Weinheim, Germany, 2003.

[130] P. Wardman, "Reduction potentials of one-electron couples involving free radicals in aqueous solution," Journal of Physical and Chemical Reference Data, vol. 18, no. 4, pp. 1637$1755,1989$.

[131] R. B. Cundall, R. Rudham, and M. S. Salim, "Photocatalytic oxidation of propan-2-ol in the liquid phase by rutile," Journal of the Chemical Society, Faraday Transactions 1, vol. 72, pp. 1642-1651, 1976.

[132] D. T. Sawyer and M. J. Gibian, "The chemistry of superoxide ion," Tetrahedron, vol. 35, no. 12, pp. 1471-1481, 1979.

[133] K. Okamoto, Y. Yamamoto, H. Tanaka, M. Tanaka, and A. Itaya, "Heterogeneous photocatalytic decomposition of phenol over anatase powder," Bulletin of the Chemical Society of Japan, vol. 58, no. 7, pp. 2015-2022, 1985.

[134] H. Gerischer and A. Heller, "The role of oxygen in photooxidation of organic molecules on semiconductor particles," Journal of Physical Chemistry, vol. 95, no. 13, pp. 5261-5267, 1991.

[135] C. Creutz, B. S. Brunschwig, and N. Sutin, "Interfacial charge-transfer absorption: 3. Application to semiconductormolecule assemblies," Journal of Physical Chemistry B, vol. 110, no. 50, pp. 25181-25190, 2006.

[136] W. R. Duncan and O. V. Prezhdo, "Theoretical studies of photoinduced electron transfer in dye-sensitized $\mathrm{TiO}_{2}$," Annual Review of Physical Chemistry, vol. 58, pp. 143-184, 2007.

[137] L. G. C. Rego and V. S. Batista, "Quantum dynamics simulations of interfacial electron transfer in sensitized $\mathrm{TiO}_{2}$ semiconductors," Journal of the American Chemical Society, vol. 125, no. 26, pp. 7989-7997, 2003.

[138] A. G. Agrios, K. A. Gray, and E. Weitz, "Narrow-band irradiation of a homologous series of chlorophenols on $\mathrm{TiO}_{2}$ : charge-transfer complex formation and reactivity," Langmuir, vol. 20, no. 14, pp. 5911-5917, 2004.

[139] S. Kim and W. Choi, "Visible-light-induced photocatalytic degradation of 4-chlorophenol and phenolic compounds in aqueous suspension of pure titania: demonstrating the existence of a surface-complex-mediated path," Journal of Physical Chemistry B, vol. 109, no. 11, pp. 5143-5149, 2005.

[140] M. Bledowski, L. Wang, A. Ramakrishnan et al., "Visible-light photocurrent response of $\mathrm{TiO}_{2}$-polyheptazine hybrids: evidence for interfacial charge-transfer absorption," Physical Chemistry Chemical Physics, vol. 13, no. 48, pp. 21511-21519, 2011.

[141] R. A. Smith, Semiconductors, Cambridge University Press, Cambridge, UK, 1959.

[142] J. Tauc, R. Grigorovici, and A. Vancu, "Optical properties and electronic structure of amorphous germanium," Physica Status Solidi, vol. 15, no. 2, pp. 627-637, 1966.

[143] P. K. Basu, Theory of Optical Processes in Semiconductors: Bulk and Microstructures, Clarendon Press, Oxford, UK, 1997.

[144] T. P. McLean, "The absorption-edge spectrum of semiconductors," in Semiconductor Program, A. F. Gibson, Ed., vol. 5, pp. 53-102, Heywood, 1960.
[145] J. I. Pankove, Optical Processes in Semiconductors, PrentienceHall, Upper Saddle River, NJ, USA, 1971.

[146] D. Dragoman and M. Dragoman, Optical Characterization of Solids, Springer, Berlin, Germany, 2001.

[147] P. Kubelka, "New contributions to the optics of intensely light-scattering materials," Journal of the Optical Society of America, vol. 38, no. 5, pp. 448-457, 1948.

[148] P. Kubelka, "New contributions to the optics of intensely light-scattering materials. Part II: nonhomogeneous layers," Journal of the Optical Society of America, vol. 44, no. 4, pp. 330-335, 1954.

[149] P. Kubelka and F. Munk, "Ein Beitrag zur Optik der Farbanstriche," Zeitschrift fuer technische Physik, vol. 12, no. 11, pp. 593-601, 1931.

[150] W. W. Wendlandt and H. G. Hecht, "Reflectance Spectroscopy," in Chemical Analysis, P. J. Elving and I. M. Kolthoff, Eds., vol. 21, p. 298, Interscience, New York, NY, USA, 1966.

[151] A. P. Finlayson, V. N. Tsaneva, L. Lyons, M. Clark, and B. A. Glowacki, "Evaluation of Bi-W-oxides for visible light photocatalysis," Physica Status Solidi (A) Applications and Materials, vol. 203, no. 2, pp. 327-335, 2006.

[152] W. W. Gärtner, "Depletion-layer photoeffects in semiconductors," Physical Review, vol. 116, no. 1, pp. 84-87, 1959.

[153] M. A. Butler, "Photoelectrolysis and physical properties of the semiconducting electrode tungsten trioxide," Journal of Applied Physics, vol. 48, no. 5, pp. 1914-1920, 1977.

[154] S.-E. Lindquist, A. Hagfeldt, S. Sodergren, and H. Lindstrom, "Charge transport in nanostructured thin-film electrodes," in Electrochemistry of Nanomaterials, G. Hodes, Ed., pp. 169200, Wiley-VCH, Weinheim, Germany, 2001.

[155] K. Leitner, J. W. Schultze, and U. Stimming, "Photoelectrochemical investigations of passive films on titanium electrodes," Journal of the Electrochemical Society, vol. 133, no. 8, pp. 1561-1568, 1986.

[156] U. Stimming, "Photoelectrochemical studies of passive films," Electrochimica Acta, vol. 31, no. 4, pp. 415-429, 1986.

[157] A. J. Nozik and R. Memming, "Physical chemistry of semiconductor-liquid interfaces," Journal of Physical Chemistry, vol. 100, no. 31, pp. 13061-13078, 1996.

[158] A. J. Bard, "Design of semiconductor photoelectrochemical systems for solar energy conversion," Journal of Physical Chemistry, vol. 86, no. 2, pp. 172-177, 1982.

[159] A. Hagfeld and M. Grätzel, "Light-induced redox reactions in nanocrystalline systems," Chemical Reviews, vol. 95, no. 1, pp. 49-68, 1995.

[160] G. Hodes, I. D. J. Howell, and L. M. Peter, "Nanocrystalline photoelectrochemical cells. A new concept in photovoltaic cells," Journal of the Electrochemical Society, vol. 139, no. 11, pp. 3136-3140, 1992.

[161] A. Wahl, M. Ulmann, A. Carroy, and J. Augustynski, "Highly selective photo-oxidation reactions at nanocrystalline $\mathrm{TiO}_{2}$," Journal of the Chemical Society, Chemical Communications, no. 19, pp. 2277-2278, 1994.

[162] J. J. Kelly and D. Vanmaekelbergh, "Charge carrier dynamics in nanoporous photoelectrodes," Electrochimica Acta, vol. 43, no. 19-20, pp. 2773-2780, 1998.

[163] R. Solarska, I. Rutkowska, R. Morand, and J. Augustynski, "Photoanodic reactions occurring at nanostructured titanium dioxide films," Electrochimica Acta, vol. 51, no. 11, pp. 2230-2236, 2006.

[164] M. A. Butler and D. S. Ginley, "Prediction of flatband potentials at semiconductor-electrolyte interfaces from atomic electronegativities," Journal of the Electrochemical Society, vol. 125, no. 2, pp. 228-232, 1978. 
[165] Y. Paz, "Preferential photodegradation-why and how?" Comptes Rendus Chimie, vol. 9, no. 5-6, pp. 774-787, 2006.

[166] M. Herrmann and H. P. Boehm, "Saure Hydroxylgruppen auf der Oberfläche," Zeitschrift fuer Anorganische und Allgemeine Chemie, vol. 368, pp. 73-86, 1969.

[167] C. Kormann, D. W. Bahnemann, and M. R. Hoffmann, "Photolysis of chloroform and other organic molecules in aqueous $\mathrm{TiO}_{2}$ suspensions," Environmental Science and Technology, vol. 25, no. 3, pp. 494-500, 1991.

[168] G. Nagasubramanian, B. L. Wheeler, and A. J. Bard, "Semiconductor electrodes XLIX. Evidence for fermi level pinning and surface-state distributions from impedance measurements in acetonitrile solutions with various redox couples," Journal of the Electrochemical Society, vol. 130, no. 8, pp. 1680-1688, 1983.

[169] L. M. Peter, E. A. Ponomarev, and D. J. Fermín, "Intensitymodulated photocurrent spectroscopy: reconciliation of phenomenological analysis with multistep electron transfer mechanisms," Journal of Electroanalytical Chemistry, vol. 427, no. 1-2, pp. 79-96, 1997.

[170] D. Tafalla and P. Salvador, "Analysis of the photocurrent transient behaviour associated with flatband potential shifts during water splitting at $\mathrm{n}-\mathrm{TiO}_{2}$ electrodes," Journal of Electroanalytical Chemistry and Interfacial Electrochemistry, vol. 270, no. 1-2, pp. 285-295, 1989.

[171] J. J. Kelly and R. Memming, "The influence of surface recombination and trapping on the cathodic photocurrent at $\mathrm{p}$ type [Group] III-V electrodes," Journal of the Electrochemical Society, vol. 129, no. 4, pp. 730-738, 1982.

[172] L. Kavan, M. Grätzel, S. E. Gilbert, C. Klemenz, and H. J. Scheel, "Electrochemical and photoelectrochemical investigation of single-crystal anatase," Journal of the American Chemical Society, vol. 118, no. 28, pp. 6716-6723, 1996.

[173] W. Kang and M. S. Hybertsen, "Quasiparticle and optical properties of rutile and anatase $\mathrm{TiO}_{2}$," Physical Review B, vol. 82, no. 8, Article ID 085203, 2010.

[174] M. C. Toroker, D. K. Kanan, N. Alidoust, L. Y. Isseroff, P. Liao, and E. A. Carter, "First principles scheme to evaluate band edge positions in potential transition metal oxide photocatalysts and photoelectrodes," Physical Chemistry Chemical Physics, vol. 13, no. 37, pp. 16644-16654, 2011.

[175] Y. Wu, M. K. Y. Chan, and G. Ceder, "Prediction of semiconductor band edge positions in aqueous environments from first principles," Physical Review B, vol. 83, no. 23, pp. 235301, 2011.

[176] D. Cahen and A. Kahn, "Electron energetics at surfaces and interfaces: concepts and experiments," Advanced Materials, vol. 15, no. 4, pp. 271-277, 2003.

[177] K. Besocke and S. Berger, "Piezoelectric driven Kelvin probe for contact potential difference studies," Review of Scientific Instruments, vol. 47, no. 7, pp. 840-842, 1976.

[178] L. Kronik and Y. Shapira, "Surface photovoltage phenomena: theory, experiment, and applications," Surface Science Reports, vol. 37, no. 1, pp. 1-206, 1999.

[179] L. Kronik and Y. Shapira, "Surface photovoltage spectroscopy of semiconductor structures: at the crossroads of physics, chemistry and electrical engineering," Surface and Interface Analysis, vol. 31, no. 10, pp. 954-965, 2001.

[180] D. Cahen, G. Hodes, M. Grätzel, J. F. Guillemoles, and I. Riess, "Nature of Photovoltaic Action in Dye-Sensitized Solar Cells," Journal of Physical Chemistry B, vol. 104, no. 9, pp. 2053-2059, 2000.
[181] A. Rothschild, Y. Komem, A. Levakov, N. Ashkenasy, and Y. Shapira, "Electronic and transport properties of reduced and oxidized nanocrystalline $\mathrm{TiO}_{2}$ films," Applied Physics Letters, vol. 82, no. 4, pp. 574-576, 2003.

[182] S. Bastide, D. Gal, D. Cahen, and L. Kronik, "Surface photovoltage measurements in liquids," Review of Scientific Instruments, vol. 70, no. 10, pp. 4032-4036, 1999.

[183] F. Lenzmann, J. Krueger, S. Burnside et al., "Surface photovoltage spectroscopy of dye-sensitized solar cells with $\mathrm{TiO}_{2}$, $\mathrm{Nb}_{2} \mathrm{O}_{5}$, and $\mathrm{SrTiO}_{3}$ nanocrystalline photoanodes: indication for electron injection from higher excited dye states," Journal of Physical Chemistry B, vol. 105, no. 27, pp. 6347-6352, 2001.

[184] H. R. Sprünken, R. Schumacher, and R. N. Schindler, "Evaluation of the flat-band potentials by measurements of anodic/ cathodic photocurrent transitions," Faraday Discussions of the Chemical Society, vol. 70, pp. 55-66, 1980.

[185] H. O. Finklea, "Semiconductor electrode concepts and terminology," Studies in Physical and Theoretical Chemistry, vol. 55, pp. 1-42, 1988.

[186] Y. V. Pleskov, V. M. Mazin, Y. E. Evstefeeva, V. P. Varnin, I. G. Teremetskaya, and V. A. Laptev, "Photoelectrochemical determination of the flatband potential of boron-doped diamond," Electrochemical and Solid-State Letters, vol. 3, no. 3, pp. 141-143, 2000.

[187] A. Podborska, B. Gaweł, Ł. Pietrzak et al., "Anomalous photocathodic behavior of CdS within the urbach tail region," Journal of Physical Chemistry C, vol. 113, no. 16, pp. 67746784, 2009.

[188] K. Vinodgopal, S. Hotchandani, and P. V. Kamat, "Electrochemically assisted photocatalysis: titania particulate film electrodes for photocatalytic degradation of 4-chlorophenol," The Journal of Physical Chemistry, vol. 97, no. 35, pp. 9040-9044, 1993.

[189] D. Monllor-Satoca and R. Gómez, "Electrochemical method for studying the kinetics of electron recombination and transfer reactions in heterogeneous photocatalysis: the effect of fluorination on $\mathrm{TiO}_{2}$ nanoporous layers," Journal of Physical Chemistry C, vol. 112, no. 1, pp. 139-147, 2008.

[190] G. Rothenberger, D. Fitzmaurice, and M. Grätzel, "Spectroscopy of conduction band electrons in transparent metal oxide semiconductor films: optical determination of the flatband potential of colloidal titanium dioxide films," Journal of Physical Chemistry, vol. 96, no. 14, pp. 5983-5986, 1992.

[191] G. Redmond and D. Fitzmaurice, "Spectroscopic determination of flatband potentials for polycrystalline $\mathrm{TiO}_{2}$ electrodes in nonaqueous solvents," Journal of Physical Chemistry, vol. 97, no. 7, pp. 1426-1430, 1993.

[192] D. Fitzmaurice, "Using spectroscopy to probe the band energetics of transparent nanocrystalline semiconductor films," Solar Energy Materials and Solar Cells, vol. 32, no. 3, pp. 289305, 1994.

[193] E. Burstein, "Anomalous optical absorption limit in InSb," Physical Review, vol. 93, no. 3, pp. 632-633, 1954.

[194] T. S. Moss, "The interpretation of the properties of indium antimonide," Proceedings of the Physical Society Section B, vol. 67, no. 10, article 306, pp. 775-782, 1954.

[195] B. O’Regan, M. Grätzel, and D. Fitzmaurice, “Optical electrochemistry I: steady-state spectroscopy of conductionband electrons in a metal oxide semiconductor electrode," Chemical Physics Letters, vol. 183, no. 1-2, pp. 89-93, 1991.

[196] J. Nelson, "Continuous-time random-walk model of electron transport in nanocrystalline $\mathrm{TiO}_{2}$ electrodes," Physical Review B, vol. 59, no. 23, pp. 15374-15380, 1999. 
[197] F. Fabregat-Santiago, I. Mora-Seró, G. Garcia-Belmonte, and J. Bisquert, "Cyclic voltammetry studies of nanoporous semiconductors. Capacitive and reactive properties of nanocrystalline $\mathrm{TiO}_{2}$ electrodes in aqueous electrolyte," Journal of Physical Chemistry B, vol. 107, no. 3, pp. 758-768, 2003.

[198] J. Bisquert and A. Zaban, "The trap-limited diffusivity of electrons in nanoporous semiconductor networks permeated with a conductive phase," Applied Physics A, vol. 77, no. 3-4, pp. 507-514, 2003.

[199] M. J. Cass, A. B. Walker, D. Martinez, and L. M. Peter, "Grain morphology and trapping effects on electron transport in dye-sensitized nanocrystalline solar cells," Journal of Physical Chemistry B, vol. 109, no. 11, pp. 5100-5107, 2005.

[200] M. Bailes, P. J. Cameron, K. Lobato, and L. M. Peter, "Determination of the density and energetic distribution of electron traps in dye-sensitized nanocrystalline solar cells," Journal of Physical Chemistry B, vol. 109, no. 32, pp. 15429-15435, 2005.

[201] A. M. Roy, G. C. De, N. Sasmal, and S. S. Bhattacharyya, "Determination of the flatband potential of semiconductor particles in suspension by photovoltage measurement," International Journal of Hydrogen Energy, vol. 20, no. 8, pp. 627630, 1995.

[202] M. F. Finlayson, B. L. Wheeler, N. Kakuta et al., "Determination of flat-band position of CdS crystals, films, and powders by photocurrent and impedance techniques. Photoredox reaction mediated by intragap states," Journal of Physical Chemistry, vol. 89, no. 26, pp. 5676-5681, 1985.

[203] J. R. White and A. J. Bard, "Electrochemical investigation of photocatalysis at CdS suspensions in the presence of methylviologen," Journal of Physical Chemistry, vol. 89, no. 10, pp. 1947-1954, 1985.

[204] G. Chen, J. M. Zen, F. R. F. Fan, and A. J. Bard, "Electrochemical investigation of the energetics of irradiated $\mathrm{FeS}_{2}$ (pyrite) particles," Journal of Physical Chemistry, vol. 95, no. 9, pp. 3682-3687, 1991.

[205] D. Mitoraj and H. Kisch, "Analysis of electronic and photocatalytic properties of semiconductor powders through wavelength-dependent quasi-Fermi level and reactivity measurements," Journal of Physical Chemistry C, vol. 113, no. 49, pp. 20890-20895, 2009.

[206] B. O’Regan, M. Grätzel, and D. Fitzmaurice, “Optical electrochemistry. 2. Real-time spectroscopy of conduction band electrons in a metal oxide semiconductor electrode," Journal of Physical Chemistry, vol. 95, no. 26, pp. 10525-10528, 1991. 


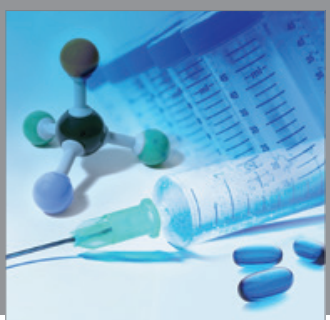

International Journal of

Medicinal Chemistry

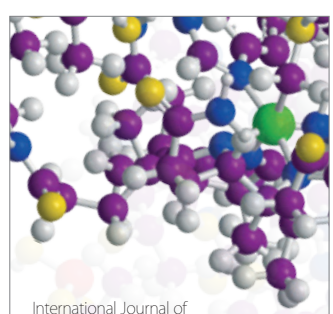

Carbohydrate Chemistry

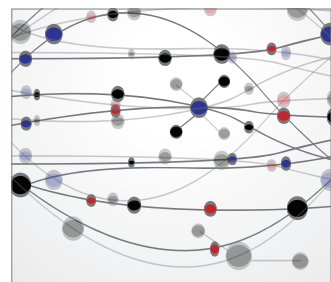

The Scientific World Journal
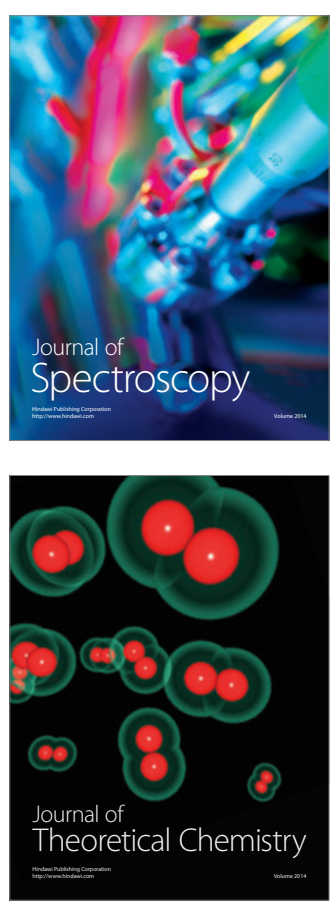
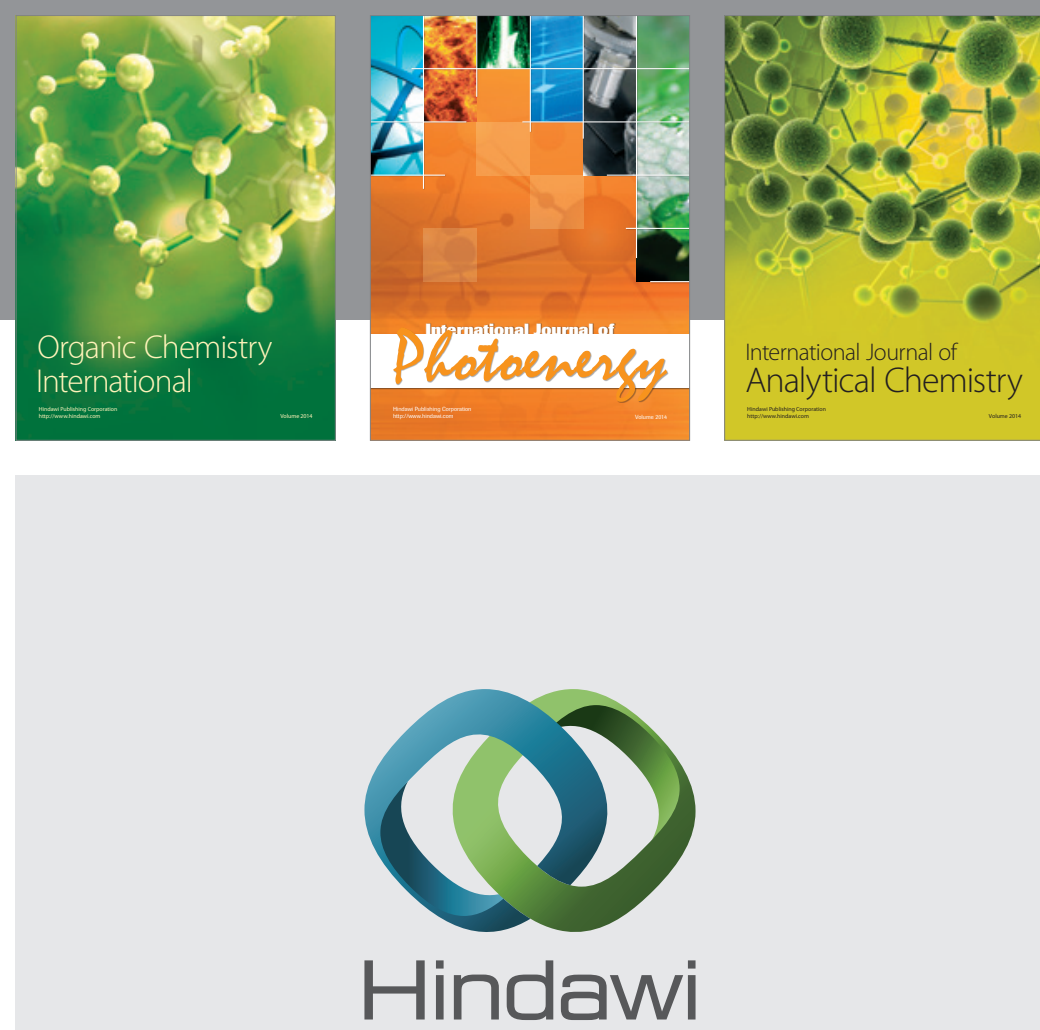

Submit your manuscripts at

http://www.hindawi.com
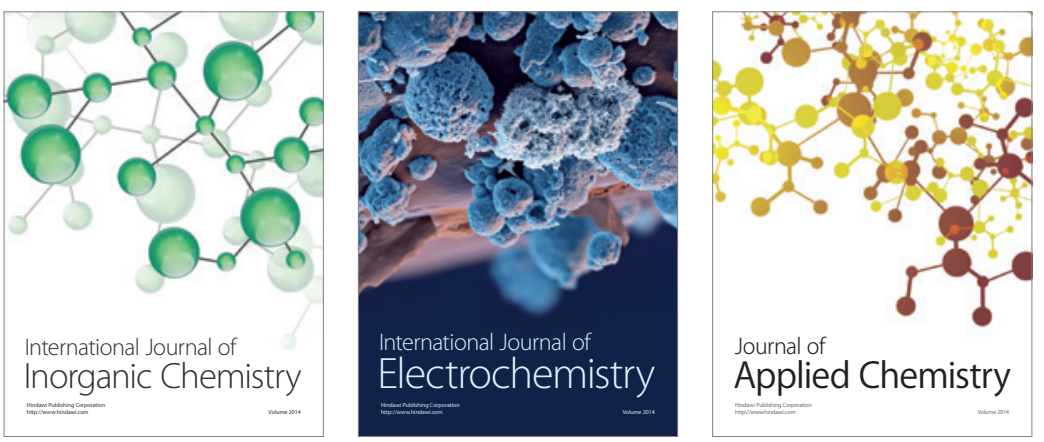

Journal of

Applied Chemistry
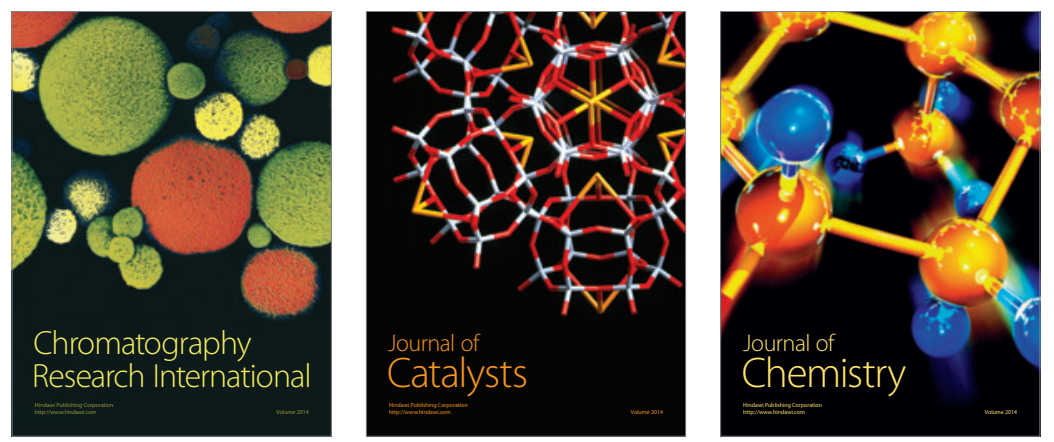
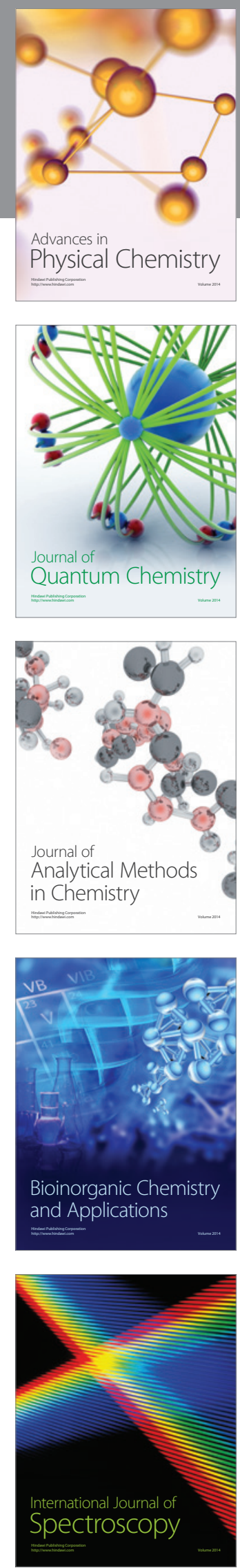